SAND79-604?

Unlimited Refeme

\title{
B77 Roll Control System: Summary Report
}

\section{MASTER}

\section{J. Pigrolet, M. H. Ropert:}

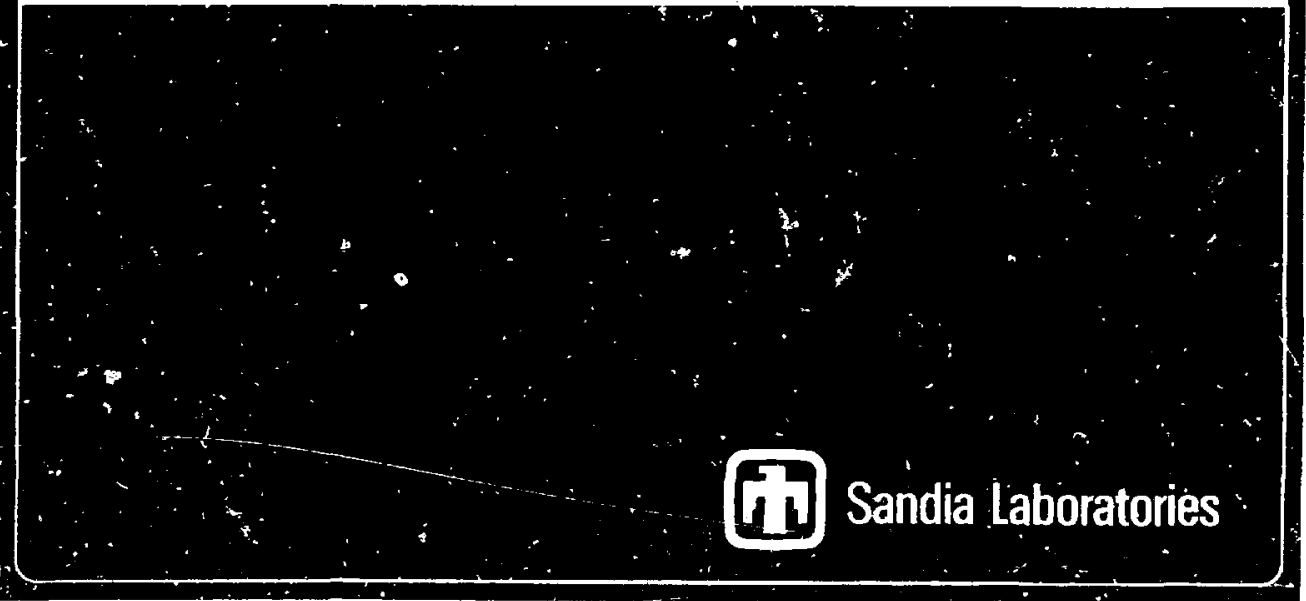

$s=2900$ a(7) 73 : 
SAND79-8047

Unl imitad Release

P.inted October 1979

B77 ROLL CONTROL SYSTEM: SUMMARY REPCRT

C. J. Pigriglet

Solar Components Division I, 8451

and

M. H. Ragers

W84 Project Division 8162

Sandia Laboratories, Livermore

ABSTRACT

The B77 roll control system evr'yed from a cold-gas driven assembly at its inception in 1974 to a warm-gas version a. the time of program cancellation in 1978. This report documents that evolvement. Included are descriptions of the analytical support calculations, the hardvare, and the test results. We detail the problems encountered and the raticnale which led to desigr choices. Although some problems had not been resolved as of cancellation, the designs provided the capability to meet $B 77$ requirements. 


\section{ACRONYMS}

$\begin{array}{ll}\text { DTU } & \text { Drop Test Unit } \\ \text { EMR } & \text { Electromagnetic Radiation } \\ \text { FDL } & \text { Flight Oynamics Laboratory } \\ \text { GG } & \text { Gas Generator } \\ \text { GTU } & \text { Ground Test Unit } \\ \text { KCAS } & \text { Knots Cal ibrated Air Speed } \\ \text { PTU } & \text { Parachute Test Unit } \\ \text { RCS } & \text { Roll Control Systents } \\ \text { RFQ } & \text { Request for Quotation } \\ \text { RTV } & \text { Room Temperature Vulcanizing } \\ \text { SLL } & \text { Sandia Laboratories Liverimore } \\ \text { TTR } & \text { Tonopah Test Range } \\ \text { WR } & \text { War Reserve }\end{array}$




\section{CONTENTS}

\section{$\underline{\text { Page }}$}

Intraduction 9

System Overview 9

Reaction System Hardware $\quad 12$

Cold Gas Roll Control System 12

Mod-0 Hot (Warm) Gas Control System 13

Mod-1 Warm Gas Roll Control System 13

Mod-2 (WR) Warm Gas Roll Control System 23

Test Results : $\quad 28$

Cold Gás Roll Control Testing ' 28

Mod-0 Warm Gas Ro11 Control Testing 30

Mod-1 Warm Gas Roll Control Testing 32

Summary : : 33

References $\quad 35$ 


\section{ILLUSTK, TIONS}

Figure

Page

1. B77 Roll Control System Components

2. B77 Roll Control Algorithm

3. Hot Gas Roll Control Interface

14-15

4. Mod-1 Roll Control System 16

5. Roll Control Valve Assembiy 19

6. Warm Gas Roll Control Interface

$20-21$

7. Mod-1 Roil Control Subassembly 22

8. Mod-2 Gas Generator Assembiy (MC3212) 27

9. Mod-2 (WR) Ground Test Assembly 
B77 ROLL CONTROL SYSTEM: SUMMARY REPORT

Introduction

The purpose of this document is to summarize the development status of the 877 roll control system (P.CS) design at the time the B77 program was cancelled. The intent is to provide a record for any potential user of a like or similar jet reaction system as it might apply to some future application. With this in mind, we have included some of the history of and rationale for the design decisions made at various stages of development, as well as discussion of the problems encountered. Also included are descriptions of the various system components and brief summaries of the numerous ground and flight tests.

\section{System Overview}

The roll control system performed a number of specific functions during the various delivery modes of the B77. For the high-altitude free-fall delivery mode, the RCS provided the torque required to spin the bomb to the 4 revolutions per second required for aerodynamic stability. For the low-altitude laydown delivery mode, the RCS maintained the upright orientation of the bomb prior to deployment of the lifting parachute. Under certain sonditions, sufficient torque was available to maintain this upright orientation throughout the lifting parachute phase of the delivery. One additional requirement was imposed on the system when the 877 was delivered in the laydown mode from the lower carriage position of a B-52 aircraft: The bamb :vas carried at approximately 37 degrees from the upright position, which required the RCS to correct this orientation prior to the parachute deployment.

The reguiremerits stated above determined the general system design parameters. The spin-up function required a torque impulse of approximately $720 \mathrm{ft}-1 \mathrm{~b}-\mathrm{sec}$. The roll control of the bomb and the $1 \mathrm{ifting}$ parachate required that torque be available for approximately 2 seconds. Additiona? requirements, imposed by a desire to minimize the tine required to perform the 37-degree rall maneuver, dictated a minimum system frequency response of $50 \mathrm{~Hz}$ and required a constant output torque. Since gas generator output characteristics vary considerably with temperature, a pressure regulator was required to control the gas generator output. 
Figure I shows the major system components and how they are interconiected. The gas generator, thrust valves, and relief valves are integrated into a mechanical unit called the reaction system, which was the responsibility of Division 8158. A later section in this report provides a more detailed description of this subsystem. The basic reaction system specifications were to provide a nominal output torque of $360 \mathrm{ft}-1 \mathrm{~b}$ for 2 seconds over a tamperature range if $-65^{\circ} \mathrm{F}$ to $+165^{\circ} \mathrm{F}$. The rate sensor, designated the SA2590, was developed by Division 2326. It provided a voltage output proportional to roll rate for vehicle rates up to $+1-250$ degrees per second. The integrator/buffer, the switching fecoder, and the valve drivers were all contained in the roll control module of the $B 77$ programmer. This electronic package integrated the roll rate signal to obtain roll angle and used both signals, along with control inputs, to provide the valve control required for proper vehicle orientation. More specific information regarding the roll control module is available in the final report on the B77 programmer.*

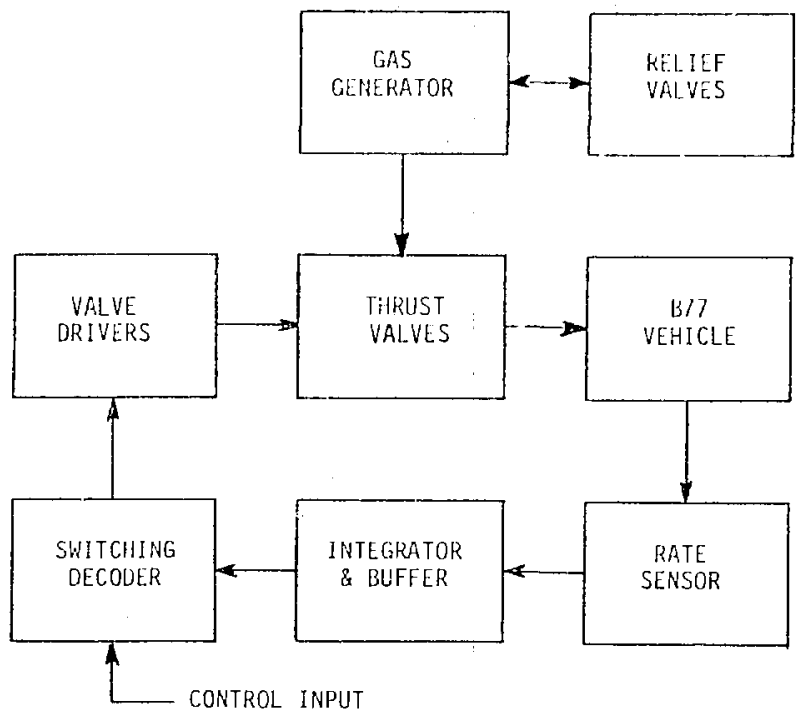

Figure 1. 877 Ro11 Control System Components

\footnotetext{
FE. L. Mckelvey, "NC3046: A Microprocessor-Based Programmer for the B77 Bomb," SAND78-8952, report in preparation.
} 
The control law implemented by the roll control modtile is shown in the phase-plane plot on Figure 2. The origin of the plot is the commanded roll position and roll rate. The various zones defined on the plot specify the active control valves and, therefore, the thrust required to drive the vehicle to the command orientation. The $220-d e g r e / / 5 e c$ limits on zone $E$ are needed to prevent saturation of the rate sensor. The slope of the control lines is a function of roll dynamics and is chosen to minimize the 37-degree maneuver time. With in the inner Zones $A$ and $C$, only two pairs of valves are active to provide a minimum limit cycle anplitude.

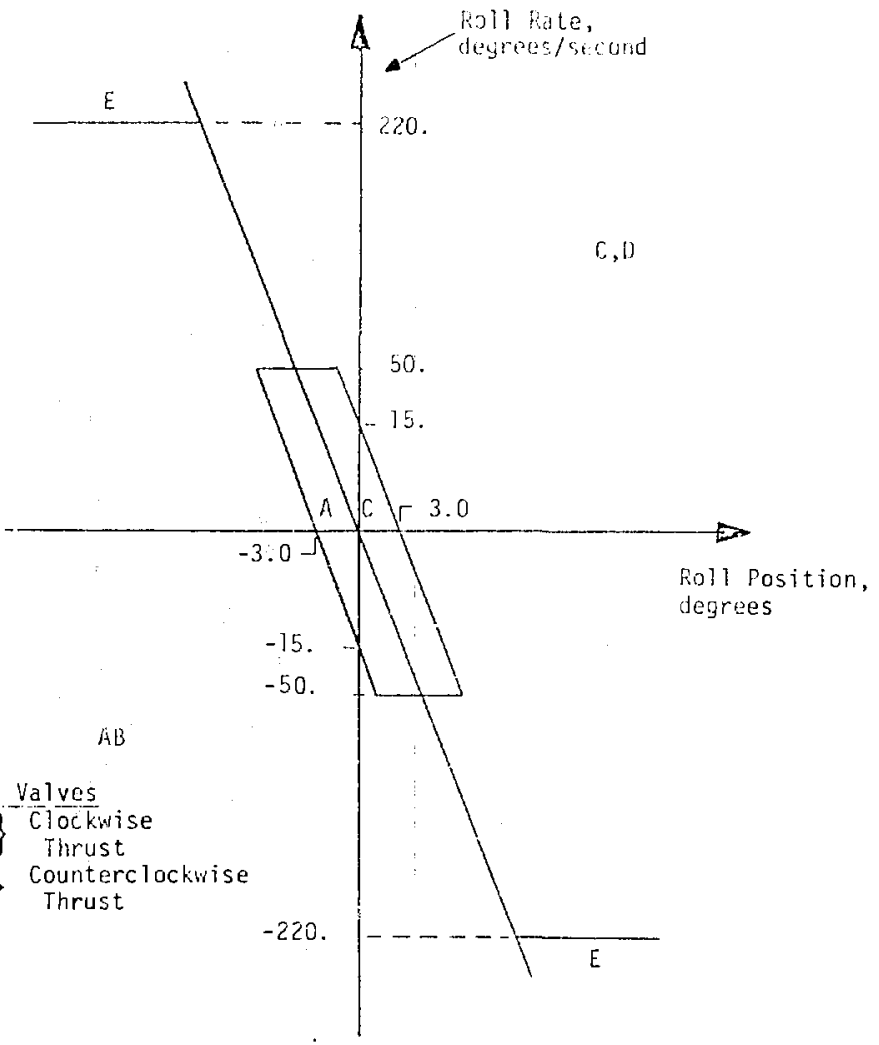

Figure 2. B77 Roll Control A]gorithm 
During the various phases of testing and evaluation of the B7? ro!l control system, a number of significant system-related problens weie encruntered. A phenomenon caused by an interaction between roll contrui gas jets and vehicle fins tended to reduce the effective roll torque being applied to the vehicle. Wind tunnel tests designed to model tiris phenomenon indicated the magnitude of the degradation to be a function of various parameters, such as Mach number vehicle orientation, and thrust nozzle configuration. Peterson and Everett 1 indicated there was a torque degradation of 4 to 15 percent. A second problem encuuntered during the 877 flight test series was that the roll control jets generated aerodynunic forces which tended to produce a yawing motion of the test vehicle. This effect, which was not apparent during wind tunnel testing, would require additional testing and analys is to understand its overall effect on system perfomance.

To aid in the design and evaluation of the various systern components, a mathematical model was deveioped aid implemcries on SLL's CDC 6600 and on a hybrid andiog computer, the EAI 7600.? The hyorid was used primarily for real-time-in-the-loop hardware testing. The model was designed to evaluate performance on a system level, rather than a componenic leval. Thus the behavior of indivicual components vere put in empirically with available experimental data. The model was subsequentiy used tc evaluate. alternative control algorithms, optimize the control parameters, predict system performance over the range of operating environments, and aid in the evaluation of flight test results.

Reülion System Hardware

The following sections contain and historicality document the design and development of the roll contral reaction system. The reartion system includes the gas generator, the relief valves, the thrust valves, and the thrust nozzles. Included al so is a summary of the qual ification testing unique to this portion of the avera?l systerl.

\section{Cold Gas Roll Control System}

Historically, the roll control development program started in mid-1974 with a cold gas-driven system designed by Organization 8333 in response to a request fram the $B 77$ project group. A cold gas system was chosen on the basis of providing the best chance to obtain early hardware in support of lifting parachute/roll control feasibility testing. It employed state-of-the-art technology derived from other gas transfer systems, and utilized (more or less) off-the-shelf type components, i.e., squib-initiated opening valves, first- and second-stage pressure regulators, and solenoid-operated thrust control valves, all from Futurecraft Corporation of Irdustry City, California. Drawing K87624 shows the overa?1. system rmployed for static ground and subsequent flight test evaluation. Results of those tests are documented elsewhere in this report.

Although operationaliy successful, the low-torque yield-to-systen weight ratio (approximately $135 \mathrm{ft}-1 \mathrm{~b}$ vs. $\mathrm{i} 20 \mathrm{lb}$ ) was not very practical, and effort was begun to investigate more efficient hot-gas thrust systems. 
Mod-0 Hot (Warm) Gas Control System

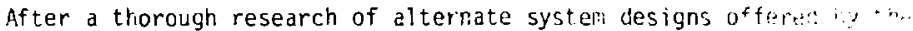
general rocket propulsion industry, it became apparent that prois. of a reliable, hiyhiy responsive control valve would te the beys:or: a sucessful hot-gas system design. We had evaluated djfferent "ia!:-

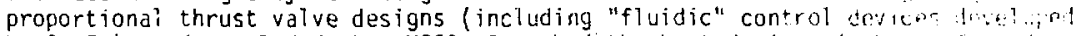
by G. E.), end concluded that MOJG, Inc. had the best design of the irerient "bang-bang" concept. It was d highly responsive, two-stage, tr:-stahle, shuttle-type valve design that they had developed and test firnver for a previous Douglas Aircraft missile application.

The order for the Mod-0 RCS (purchases order 36-2455) was lot i: early 1975 to Thiorol-Elkton, the primary system contractor for the Molc-sit od control and relief valves. The establisheo external configuration " trace valves resulted in some comproritising of thrust potentia?, packafiri, sed? inc, and weight considerations for the overall Mod-0 design, but their is did resu?t in early availability and high perfomance ipliability as the sibsequent ground and $\mathrm{fl}$ ight test programs have demonstrated. Figure 3 (plus periomanc: Specification K92lil) defines the overali Mod-0 ros that pas eniloyed for the Tonopah Test Range (TTR) ground qualification cests (GTU's) and the f'17t: test (DTU and PT'J) series which started in early 1976 and concludes : $12+e$ 1977. Results of thuse tests are dccumented el sewhere in this report, he scope and results of Thiokol's in-house developinent test progral" (which preceded Sanjia's test series) are dccumented in Thiokol's surmary repirt. E.213-75, daced December 17, 1975.

Although both the ground and flight test series were highly succssful from an operational/perfomance view, there were problems associstis with assembiy, gas leakage, heat distortion, and refurbishment canab: it: that wers inherent in the "compromised" design of the Mod-0 system.

\section{Mcd-1 Warm Gas Roll Control System}

Design and contract negotiations for the Mod-? RCS began Hichi Thiokoi/ MOOG in late 1975, with contract placement occuring in inid-ig76 (?urchese Order 86-9383). This second-stage development prograii represented an initia! effort to tailor the roly control system and its components to meet the weight, perforiance, packaging, shelf-life, and environmental requironencs of the $B 77$ bomb system. A photograph is shown in Figure 4 . Altroligh siteilar in concept to the Mod-0 design (thereby capitalizing on proven testrnology), jone of the specific features afforded by the new Mod-1 design were:

1. Use of a inigher-iurn-rate propelinnt (but of the same ip-iH-33i4 formulation as used in the Mod-0 generator), resu?ting in a higher specific impulse and more efficient thrust-to-weight ritio.

2. Replacement of the direct mounting of individual collitrol valves to the generator end closires with a single port/valve-mounting flarg: at each end. The double closureizdjustable "turnbuckie" feature of the Mod-0 generator was retained for the llod-1 developmeni test series, bit was replaced with a more eficient single-joint/bolted piessure vessel design for the non-adjutable wh version. Rupture discs were 


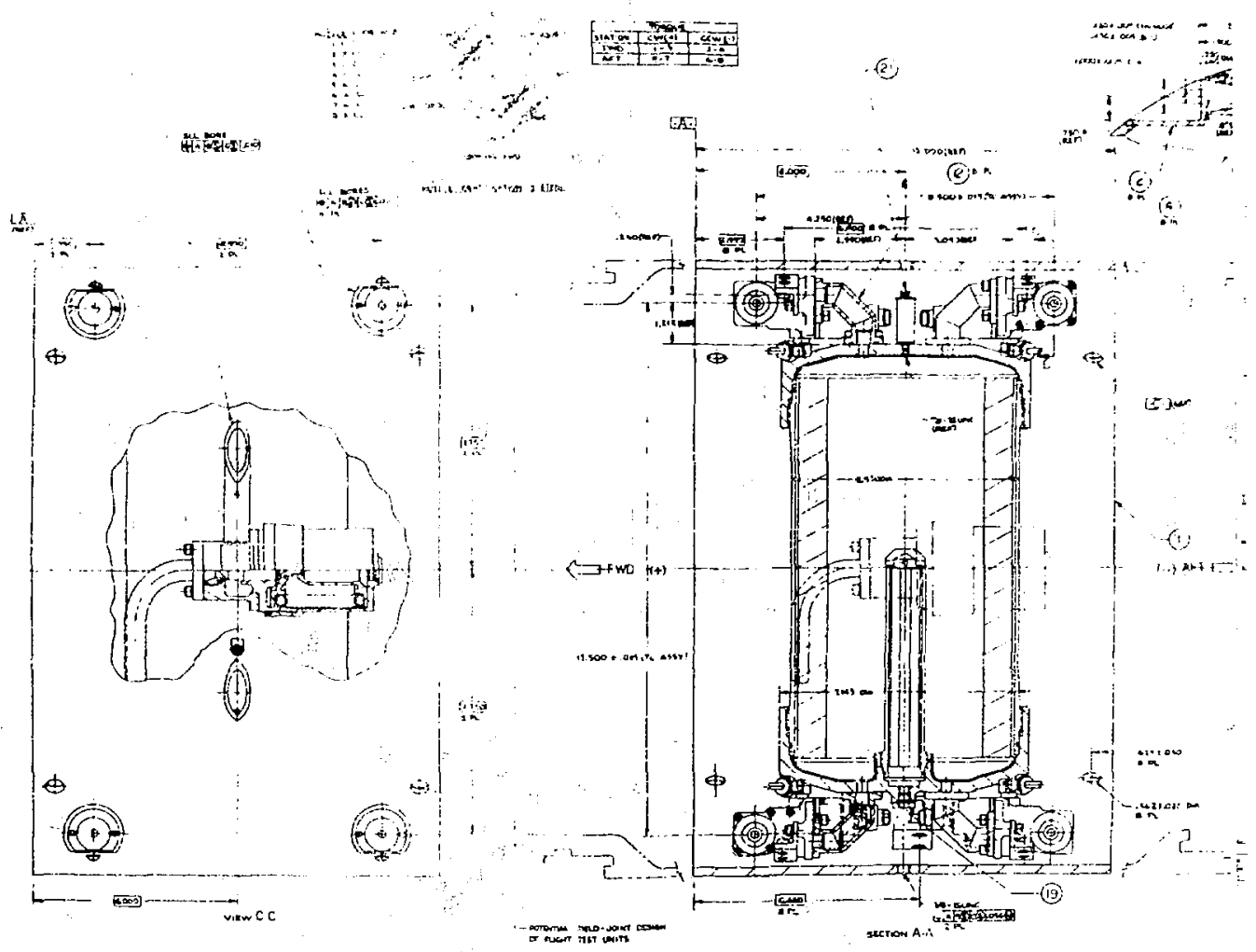

Figure 3. Hot Gas Roll Conti-- 


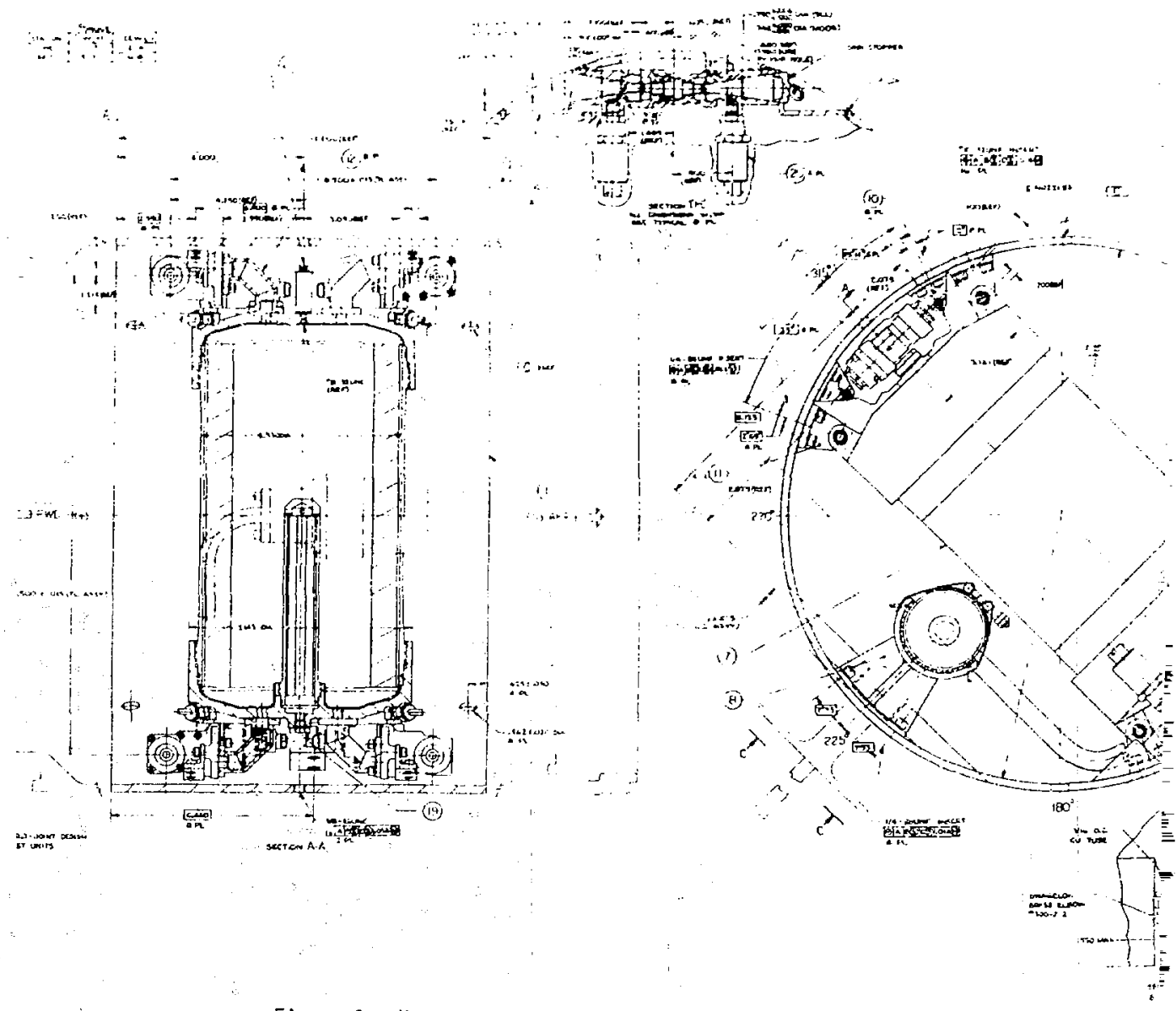

Figure 3. Hot Gas Roll Controi Interface

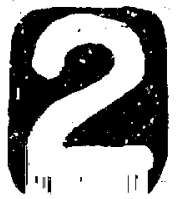



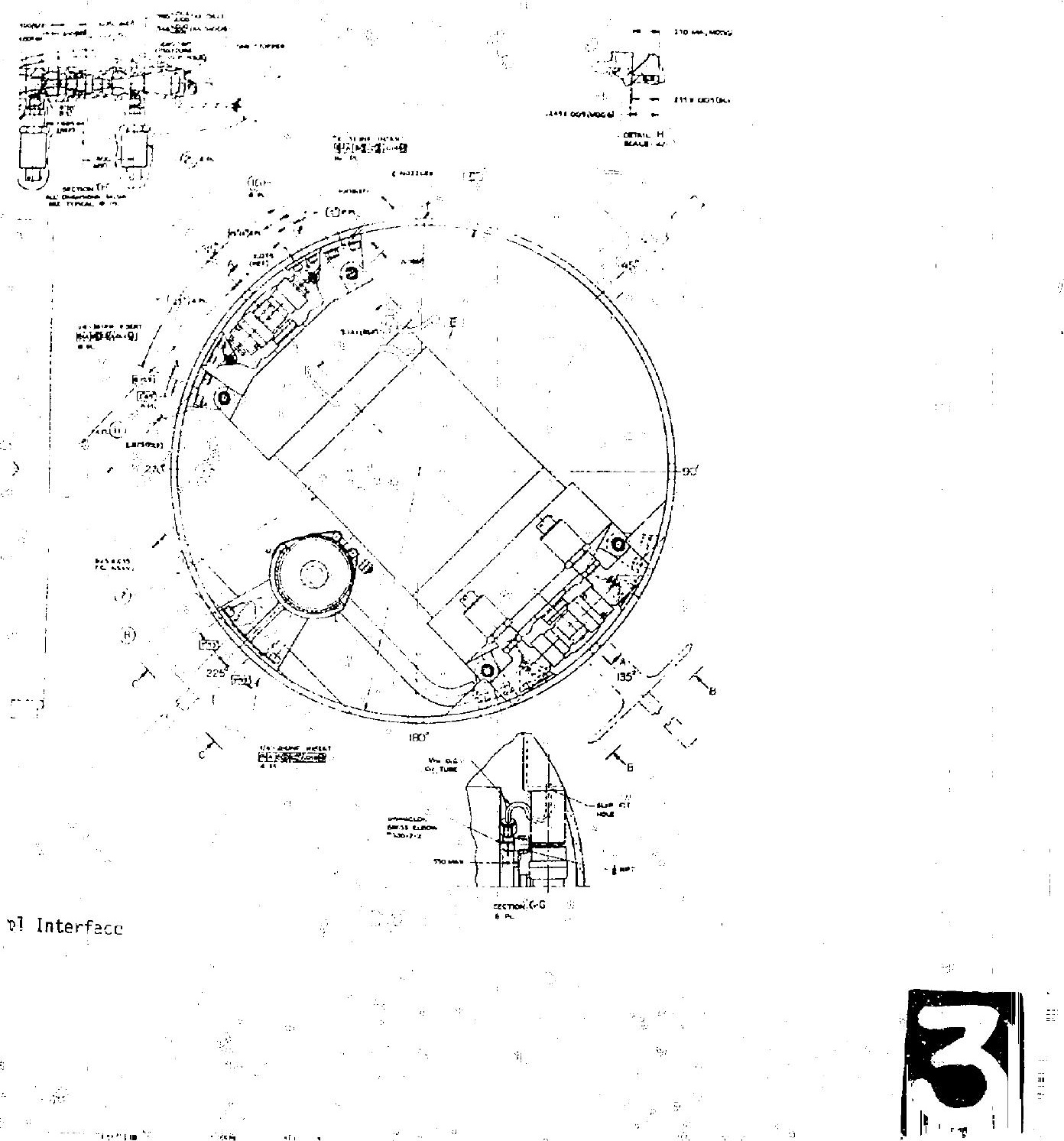


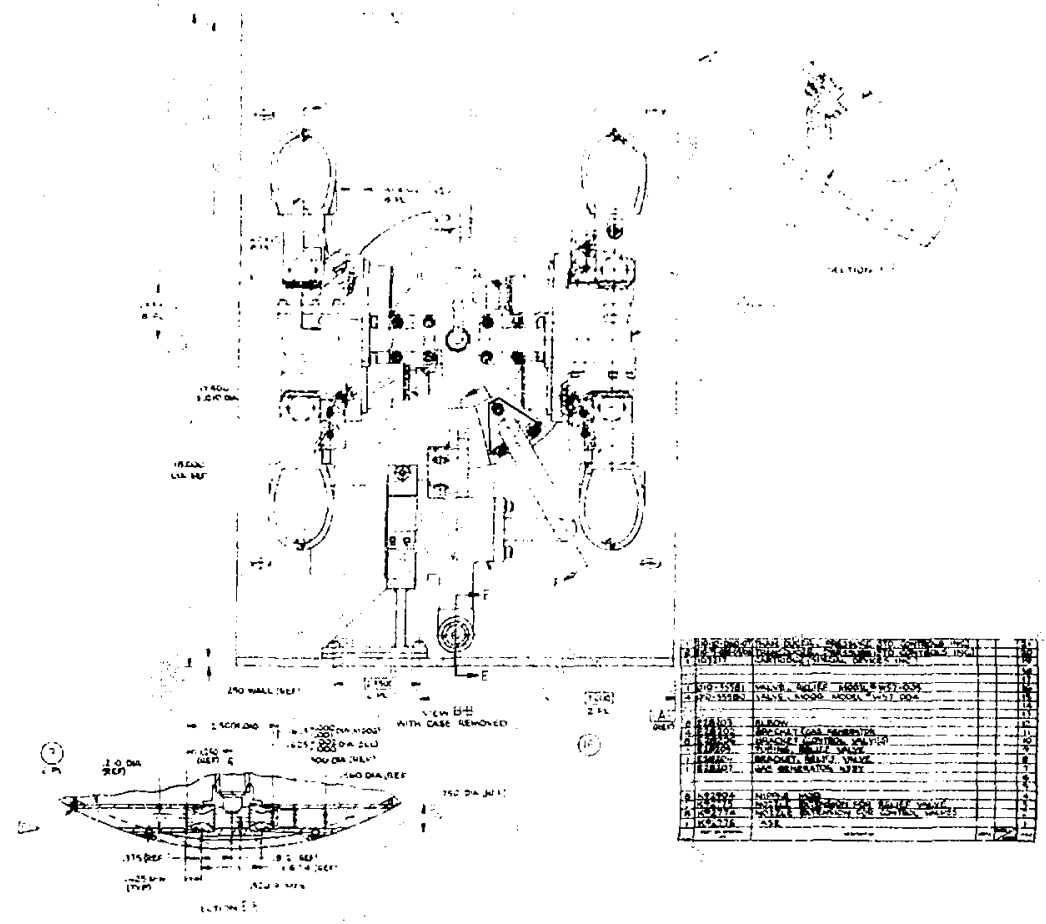




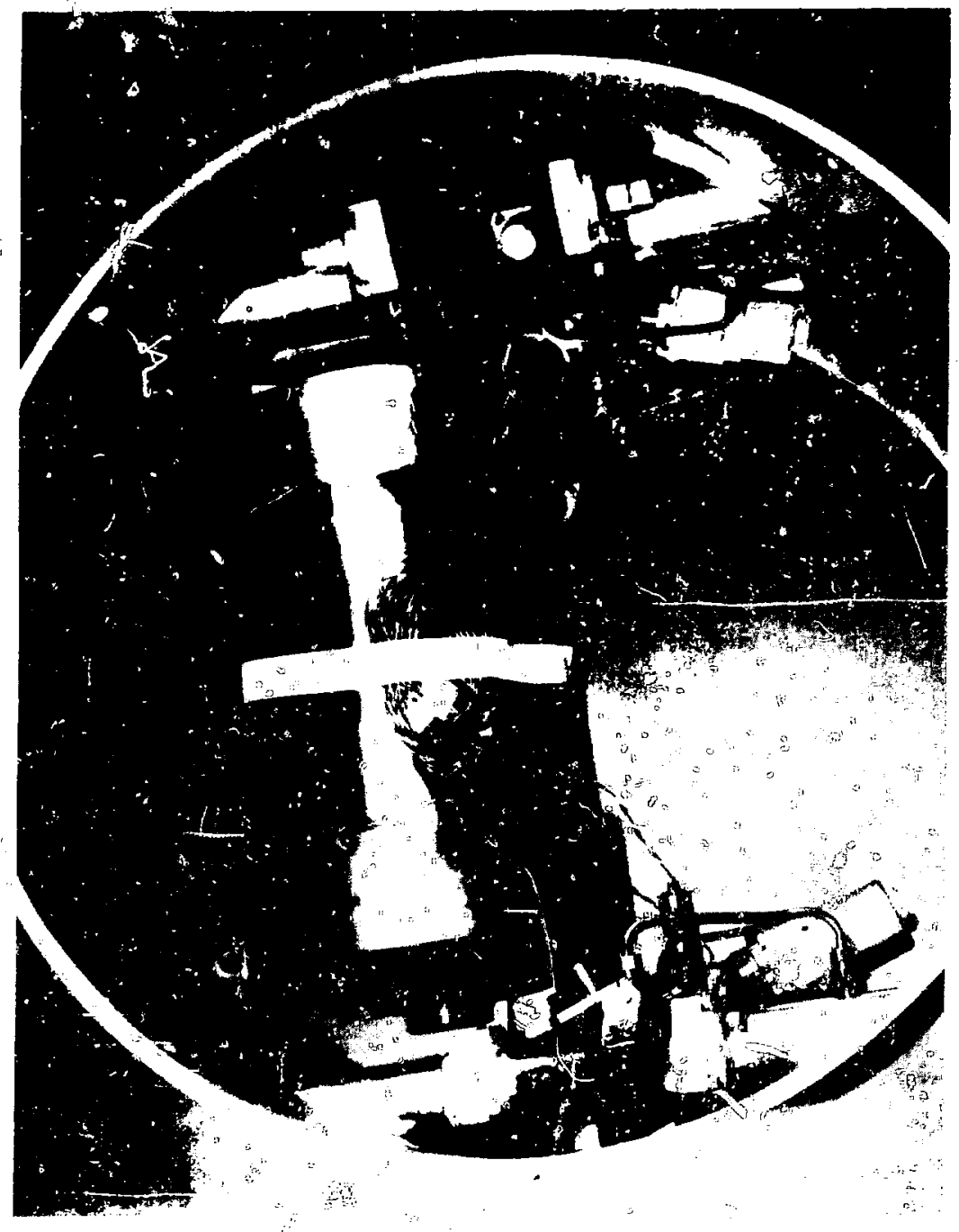

Figure 4. Mod-1 Roll Control System 
incorporated into the outlet poris at each end of the generator as a means of providing "capsule" containnerit ni the propellant. Hermetic sealing, ease of assembly, limited-life change-out (if necessary), and potential refurbishment of test-fired WR assembilies were all facilitated by the new Mod-1 generator design.

3. Integration of the previous pair of individual control valves at each end of the generator into a dual control/relief valve unit assembly incorporating the collowing features (Figure 5):

a. The new dual valve assemblies were secsured directly to the aft case wali, with the iritegraced relief valie exna'isting radially trirough the case wall at the centerline of each unit asssambly. The resulting "pair" of relief valves in the system enhanced overa! reliability in that a single relief valve (with the cross talk tube interconnecting) would still prevent over-pressurization of the system in the event one relief valve failed to function. Besides eliminating the separate relief valve mounting and the troublesome generator-to-relief valve tube required in the Mod- 0 design, the radial porting of the exhuast guses el iminated the derodynamic pitch/yaw influence which tangential porting caused in the Eariy Mod-0) fijght units.

b. The integral valve manifold/mounting flange permitted a simple tace-seai conrection for the gas generdiur, with a $20^{\circ}$ face angie accorrmodating overail dimensional tolerances.

c. Hew "balanced pressure" poppet design in pilot stage operation of control valves el iminated pressure-sensitive limitation of prior Mod-0 "ball check" design.

d. Grientation of the pilot stage/solenoid axis was changed to be lateral to the vehicle axis (versus axial in Mod-0), thus minimizing affects of parachute deceleration loads oi valve performance.

e. New valve design was "sized" to permit doubling of pressure/ thrust output as an optional capability.

In sitmary, the new Mod-1 reaction system represented a significant advancement over the prior Mod-0 design, and a major step toward an ultimate WR solution. Figures 6 and 7 (along with Performance Specification K94160) define the overall Mod-l system that was employed for the six TTR ground qualification tests and the two subsequent fight test units (PTU-20 and -37) winch occurred after program cancellation. Results of those tests are documented elsewhere in this report. Again, Thiokol conducted a prior in-house development test program sufficient to deinonstrate that the new Mod-1 design met sysiem requirements. These tests ranged in scope from individual component qualification tests (i.e., separate igniter, gas generator, relief valve, and control valve performance tests) to partial and full system performance tests. The full scope and results of these tests are documented in Thiokol's summary report EL35-77, dated December 1, 1977. 
Not withstanding the significant system improvements enumerated for the new Mod-1 cesign, ther: were al 50 new problems encountered. Some were carryovers from the Mod-0 design, but cthers were inherent in the new Mod-1 features. The following outline sul? Jrizes the design and operational status of the Mod-1 RCS as evidenced by tha sround and flight test results:

1. Use of two relief valves in parallel in the system may have enhanced safety and reliability considerations, but their interaction and new effect on system pressure regulation was not always predictable. In the initial development test series at Thiokol, the two relief valves were allowed to operate independently. As anticipated, one relief vaive cracked first and did most of the work, while the other worked at partial capacity. The new effect was unualance in the amount of exhaust gas discharged through the opposite ports. The addition of a "cross-talk" tube interconnecting the plenum chambers of the two reliuf valves alleviated the unbalance, and, at the same time, provioded an additional pressure escape route if one relief valve iailed to open.

2. One of the probleris unique to the Mod-1 design was first revealed during our ground test series at TTK, when we encountered sporadic oscillations in the regulated pressure system. It varied in amplitude and Juration, depending on the preconditioned temperature and adjusted regulating pressure of the different test units, but the frequency always began at approximately $50 \mathrm{cps}$ and gradialiy diminished to about 20 cps, at which time it ceased oscilliating, Interestingly, the new average regulated pressure during oscillation was correct and almost perfectly flat, resulting in the best regulation control we had ever experienced, including that in the Mod-0 history. Although not considered a serious problem, in the overall system performance or thrust control was not significantly degraded, the lack of understanding of this pheromenon cast a shadow of doubt on the soundness of the pending Mod-2 (GiR) design. At the time the program was cancelled, various analytical efforts were underway by SLL, MODG, and Thiokol to gain insight into the problem, but nothing was resolved.

3. Another unresolved problem unique to the Mod-1 design was the two incidents of "stickinig" first-stane valve operation. The first incident occurred, during testing of GTU-19, which consisted of an 8 rps spin-up test performed at a preconditioned temperature of $-65^{\circ} \mathrm{F}$. To achieve the torque impulse needed, all four control valves were initially commanided hard over in one direction for 1.6 seconds, and then to the null position for the bolance of the burn time. Three of the four valves responded as proyrammed, but the fourth valve stuck in the hard-over position, resulting in slight overspin of the unit. The second incident occurred on a similar test unit, only this time tire duty:cycle was preprogrammed to include a hard-over-to-hardover "dither" cycle at the conclusion of the sustained spin torque. Again, one of the valves stuck momentarily during the first "dither" cycle, but broke loose and performed nomally for the balance of the burn time. 


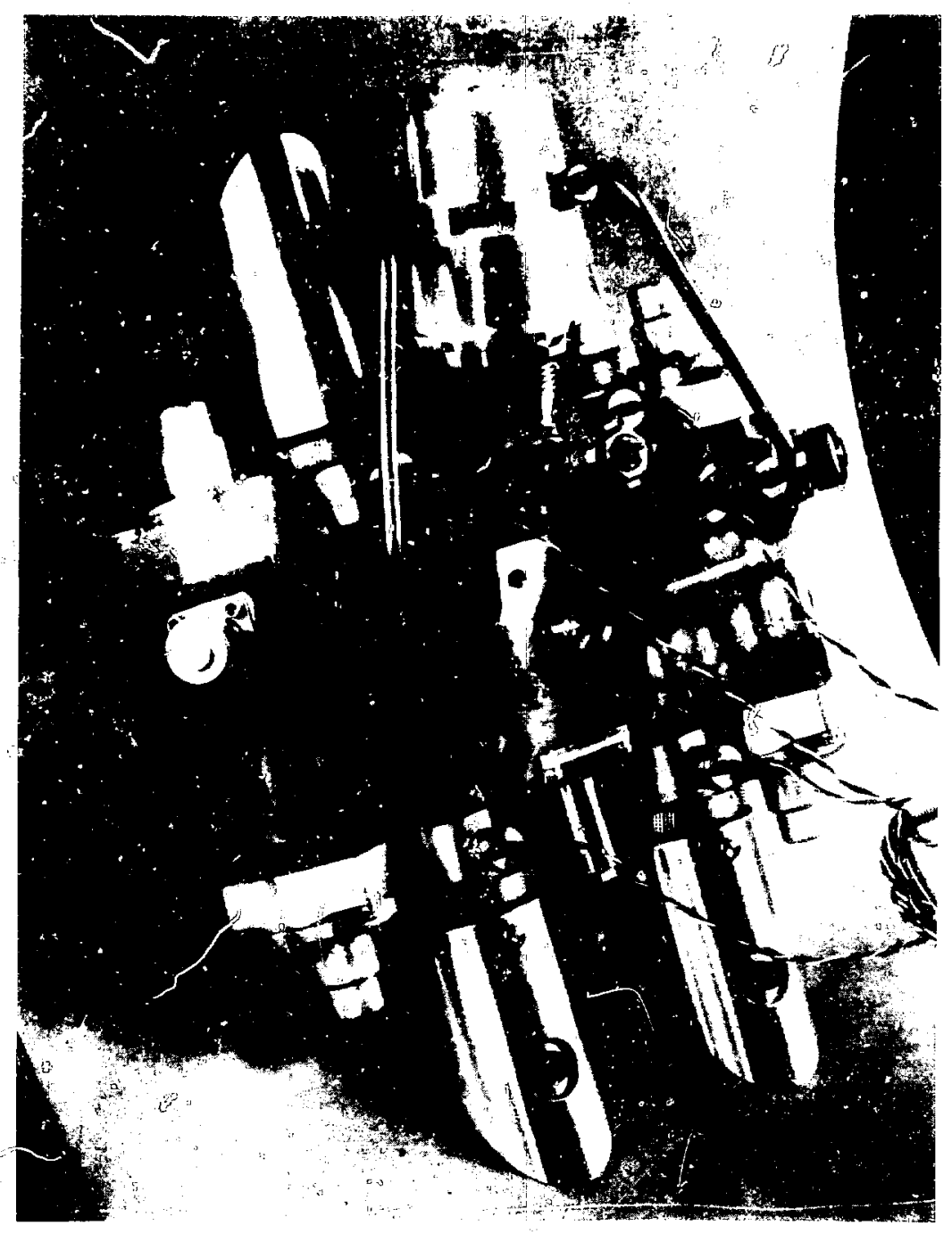

Figure 5. Roll Control Valve Assembiy 


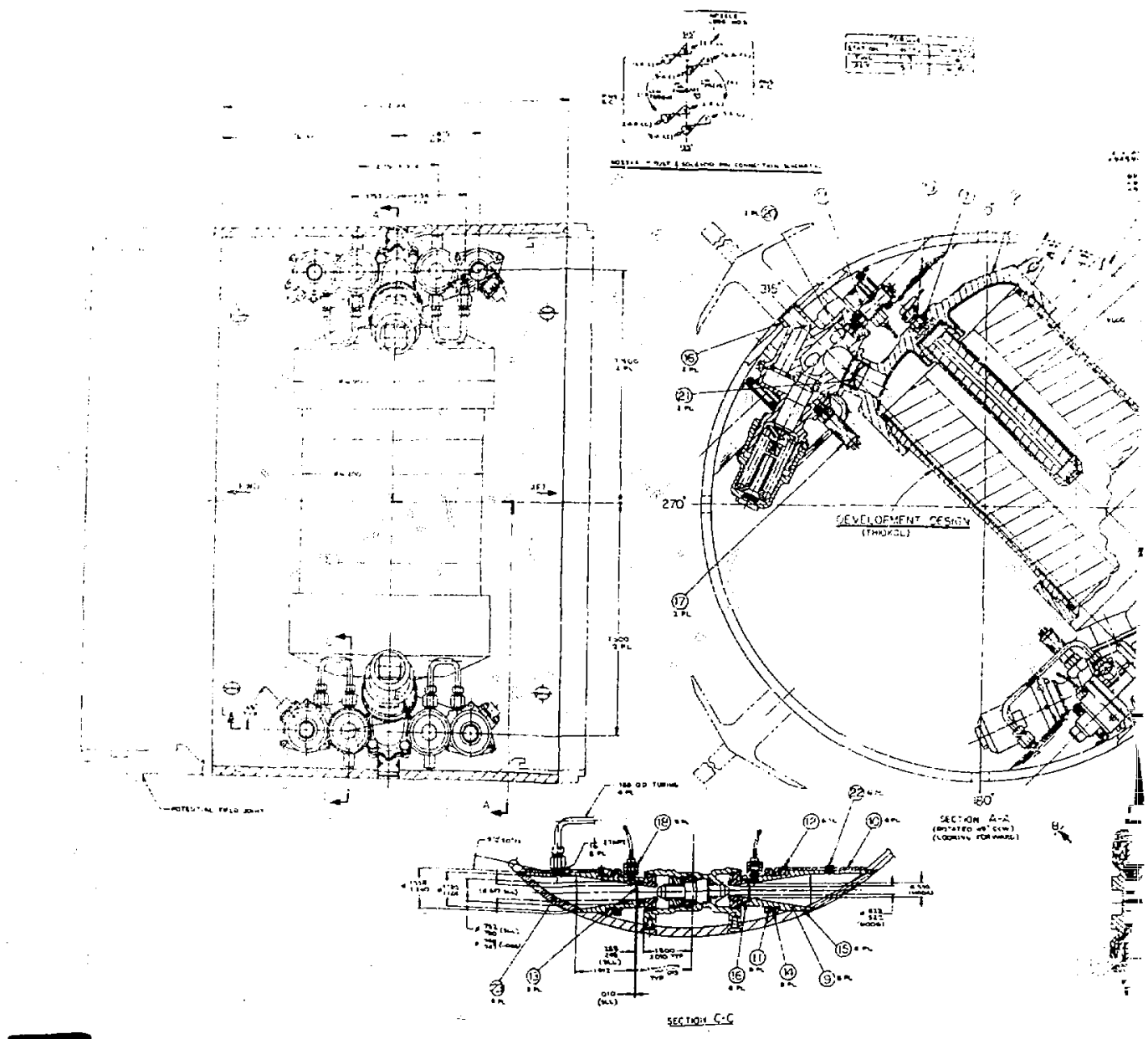

Fjgure 6. Warm Sas Roll Con 


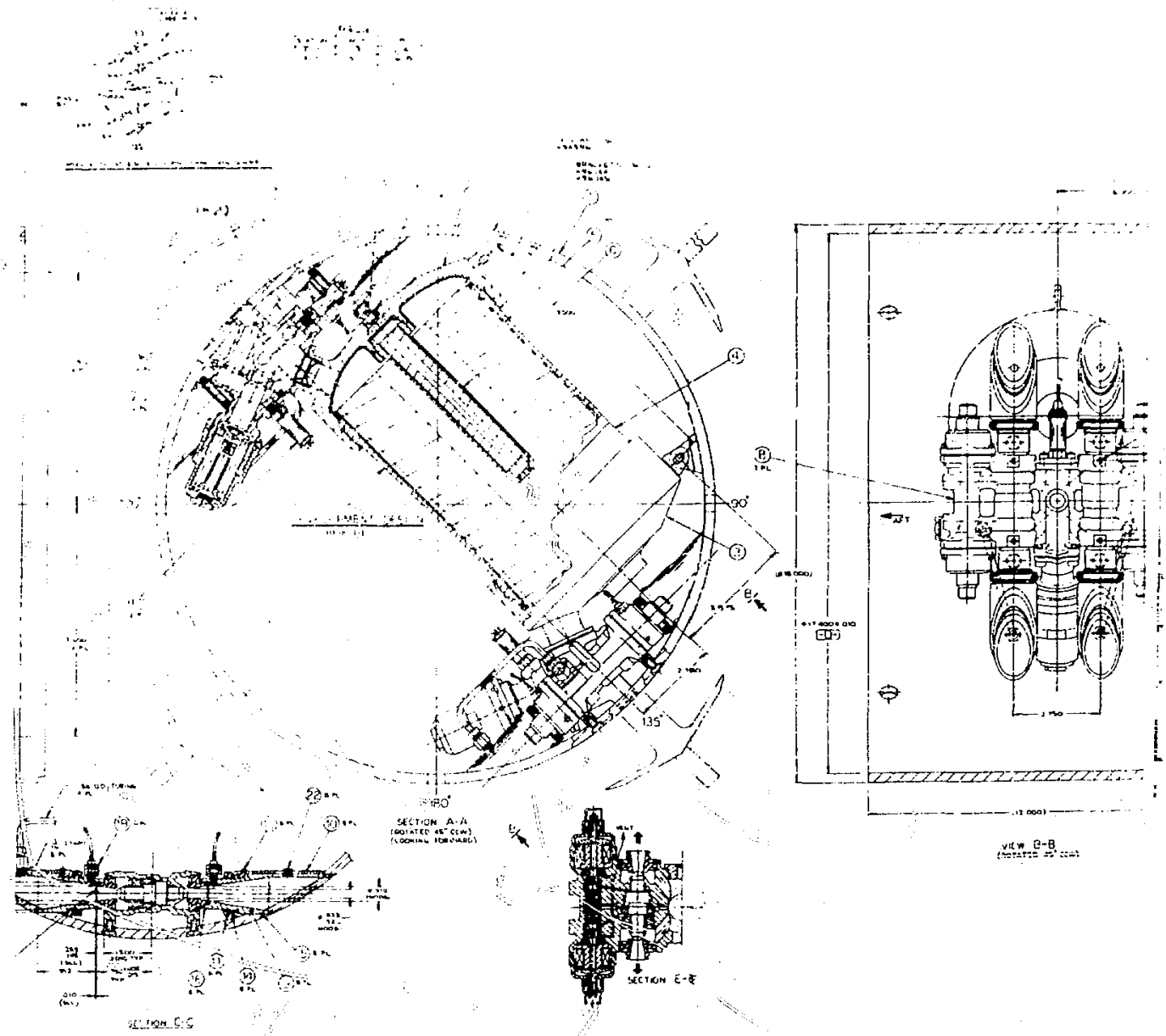

Figure 6. Warm Gás Ro1l Control Interface 


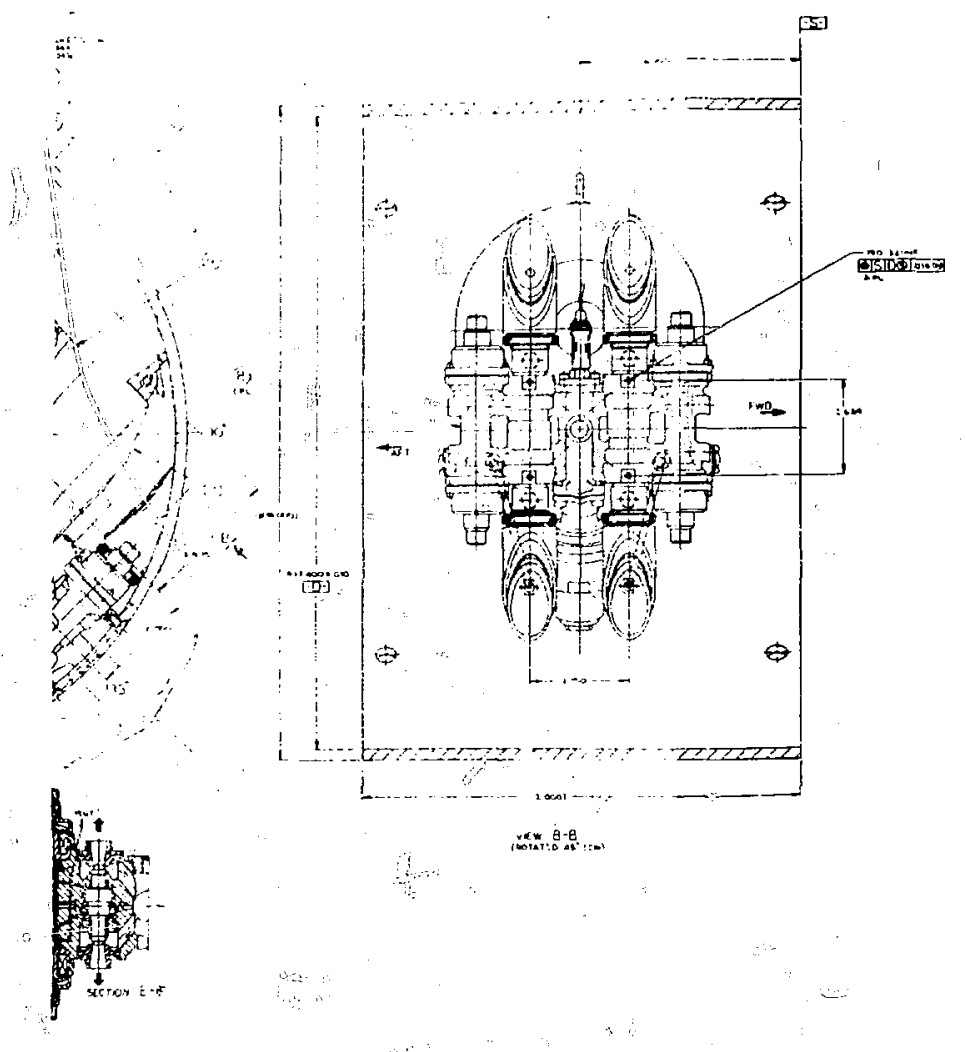

rol Interface 

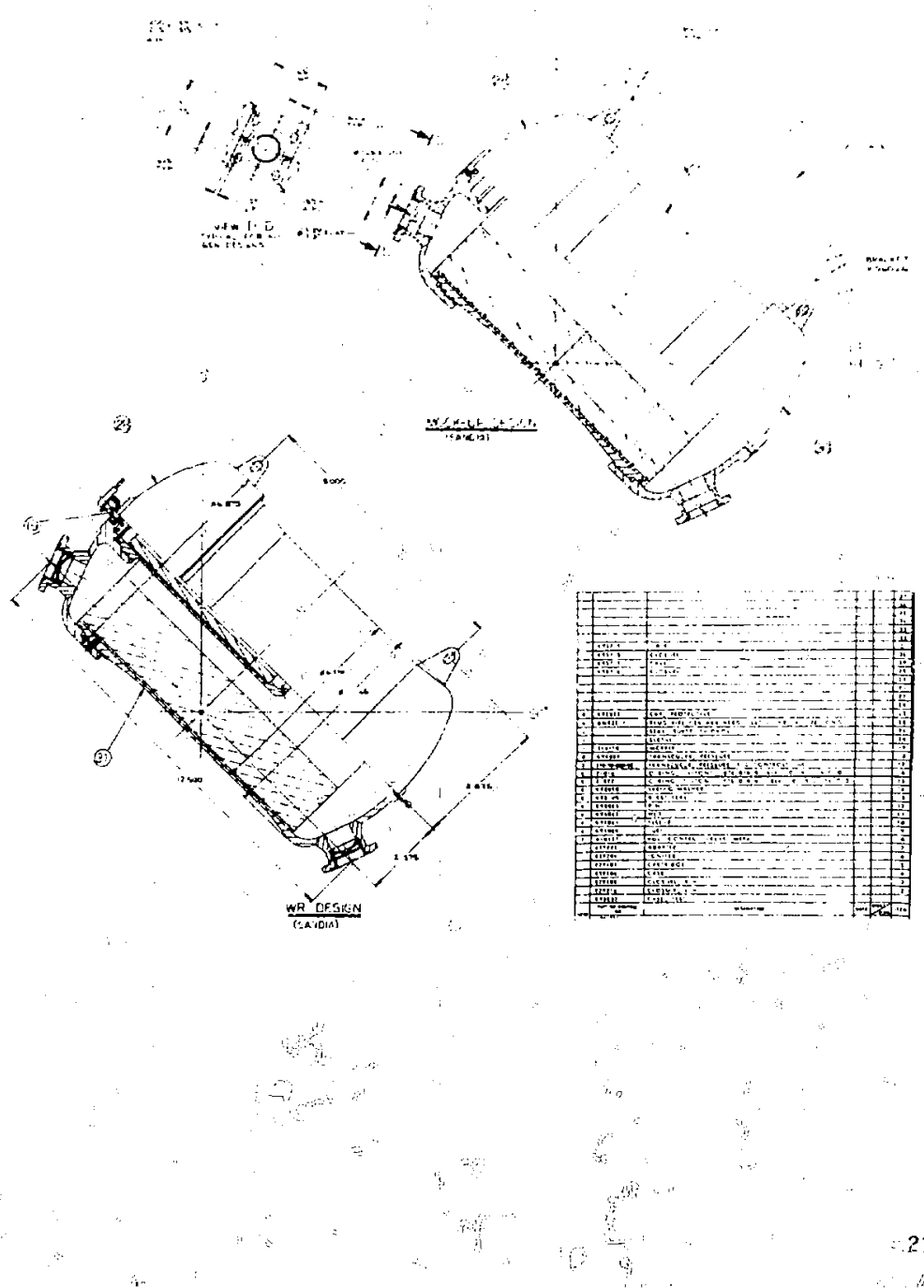


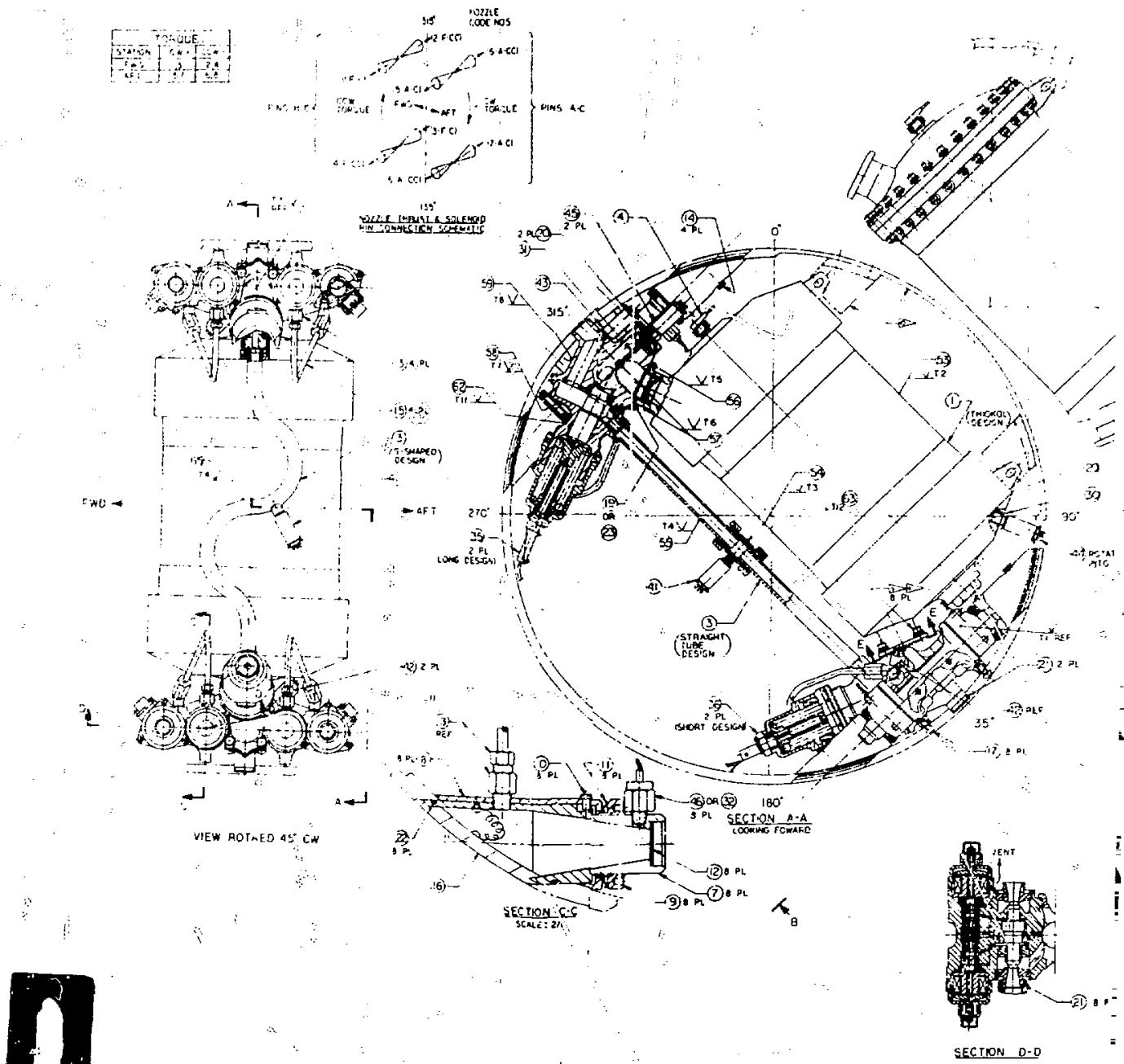

Figure 7. Mod-1 Roll Control Subassembi: 


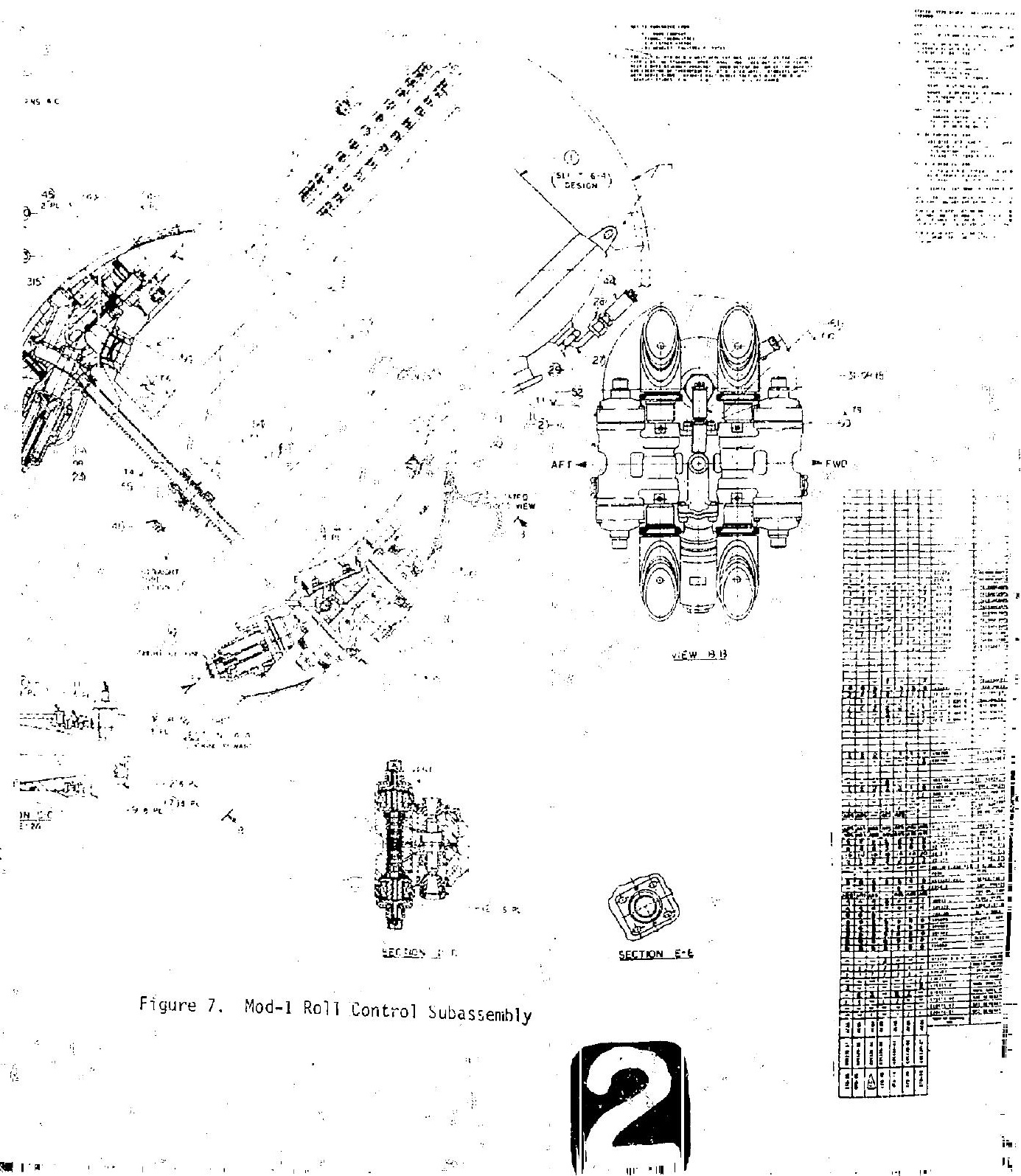



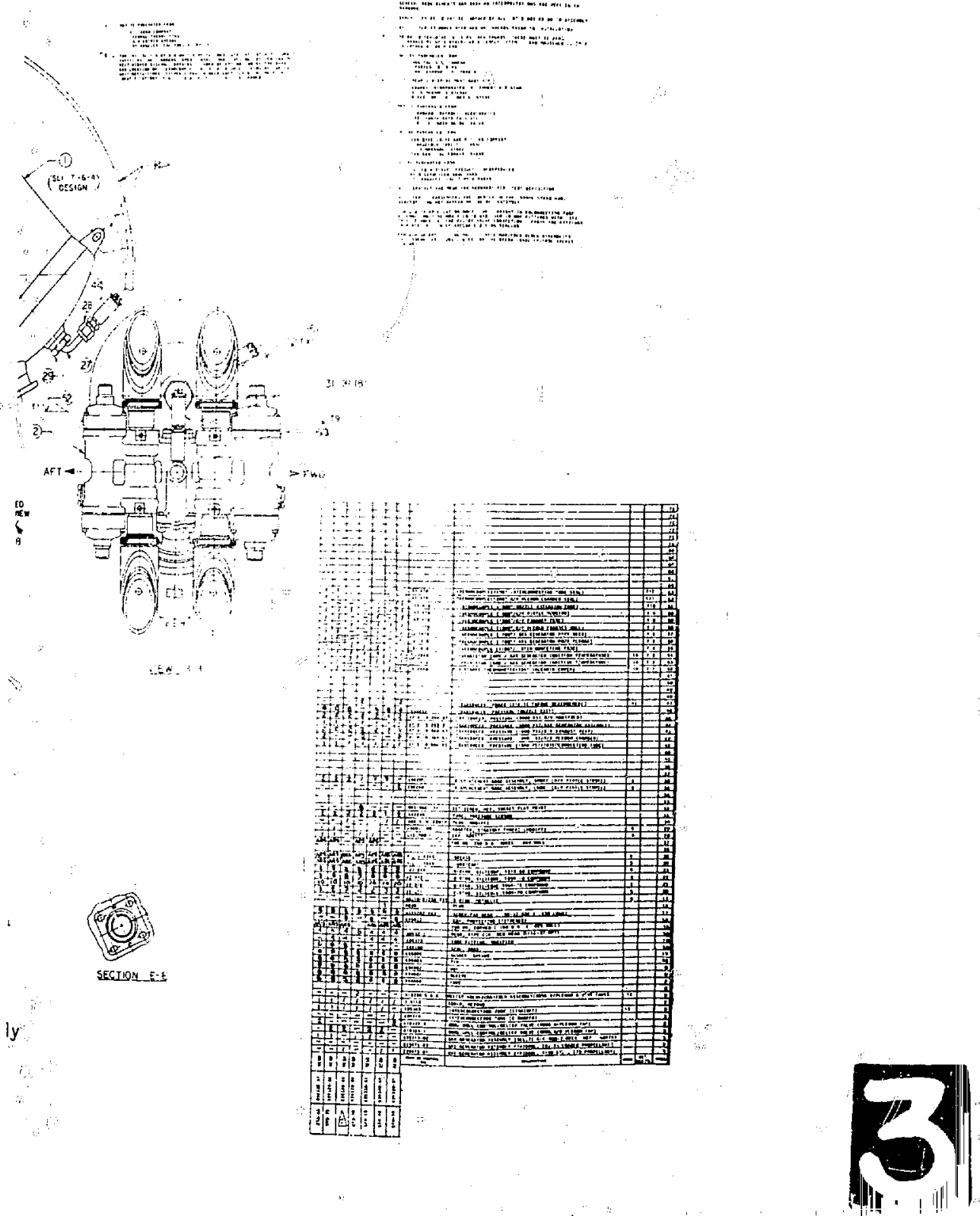
At the time the $B 77$ was cancelled, a multipla part test evaluation program was underway to isolate the cause, or at least eliminate many of the possibilities that existed. The effort did not get completed, but the consensus at the time was that sustained hard-over operation (unique to the spin-up mode) was resulting in byproducts of combustion "gluing" or otherwise restraining the poppet from returning to the null position within its preload spring force.

4. One of the carry-over problems from the Mod-0 experience was the adequacy of system sealing for both storage enviromental conditions and during hot gas uperation. Although the basic concepts of the Mod-1 design provided potential solutions to most of these problems, total solutions had not been perfected in all areas at the time of progran terminaton. The "capsule" design of the gas generator assembly did provide an effective sealing solution for protecting the propellant against environmental degradation, out the adequacy of the C-ring seal to contain the hot gas operating pressure apipeared marginal and required more developmental effort.

Similarly, the Mod-1 nozzle extension design represented a significant improvement over the Mod-0 design in so far as providing EMR and environmental sealing at the case-to-nozzle interface, but the nozzle-to-valve seal was not proven totally effective during burn operation. Several alternate rupture-type seal designs were being test evaluated at the time if program cancellation, but it became increasingly apparint that the "jack tight" installation feature of the Mod-l design has inherent loading limitations that precluded adequate face sealing.

In general, the Mod-1 test program demonstrated significant improvenent over the Mod-0 system relative to overall sealing considerations, but total solutions would have to be resolved in the (still) pending

Mod-? (WR) devel opment effort.

\section{Mod-2 (WR) Warm Gas Roll Control Syster.}

Because of the relatively long time (approximately 1-1/2 years) between design, contract placement, and eventual hardware delivery, negotiations with Thiokol and MOOG for the find Mod-2 development design were begun in mid-1977 with the intent of havigig initial test hardware available by the end of FY78. This waild have supported a fina? ground test qualification series and the beginning of our planned flight test (FTU) and reliability assessment program. At the time of program cancellations, details of the new Mod-2 design had been largely defined, and RFQ's for both the valve componerts from $M O O G$ and gas generator assemblies from Thiokol were in process for experted order placement by late January/early February 1978.

Although identical in concept to the Mod-1 system, the Mod-2 design basically optimized features of weight, cost, assembly, sealing, and/or shelf-life considerations as detemined by the Mod-1 test results and subsequent evaluations. Some of the more significant design changes incorporated in the proposed Mod-2 RCS were as follows: 
1. The adjusted regulating pressure of the two relief valves was inireased from a nominal 1800 to $2 ? 00$ psig, thereby realizing a corresponding $22 \%$ increase in torque yileld from 365 to $446 \mathrm{ft}-\mathrm{lb}$. This added operating pressure and torque output was essentially available within the existing structurai integrity of the Mod-1 RCS and so no weight penalty was involved. Use of the increased torque output was considered worthwhile in further controlling inherent parachute roll behavior.

2. One of the principal changes was a new Ti-6Al-4V nozzle extenstion design which connected directly to the control valve via a captured coupling nut. This eliminated the outer sleeve part of the previous "jack tight." concept, and also provided a tighter, more positive preload to squeeze the burst seals installed in between. It was smaller, simpler to assemble, weighed and cost less, and accommodated thermal expansion with a slip-fit through the cylindrical bore in the case wall.

3. An impact of the new nozzle design was to change the connecting interface to the control valve. The requirement for an external threaded joint to accept the nozzle coupling nut, plus the rieed for a keying feature to maintain angular orientation of the scarfed nozzle, necessitated MOOG to go to a bolted flange adapter on their valves (vs. the threaded insert on the Mod-1). Because of space limilations to incoporate the bolted flange adapter, the center-to-center distance between the trrust nozzlles had to be extended from 2.750 to 2.920 inches. Other minor changes to the vaive design were made sy M0OG to improve its sealing and regulating performance. The plenum chamber and downstream orifice of the relief valve were both enlarged and reshaped to net better flow characteristics and discharge efficiency, and the rel ief valve pintle was lightened to improve dynamic response. Also, consideration was being given to increasing the spring rate of the regulator spring, pending outcome of the oscillation problem. Because of some evidence of hot-gas leakage occurring at the relief-to-control valve interface during the Mod-1 test program, a metal C-ring was substituted for the prior elastomer face seal.

As part of a cost effective study, MOOG was evaluating the practibility of using Ti-6Al-4V investment (10st wax) castings for several of the intricate shaped parts of the valves. Prototype castings for the main control valve body, relief valve housing, and nozzle adaptars were delivered by Titech, Inc. tc MOOG just prior to program cancellation, and so tive evaluation effort was never concluded.

4. The design evolution for an ultimate WR gas generator (GG) assembly did not necessarily follow the Mod-0, $-1,-2$ development chronology. Because of the lack of dimensional precisiontypical of development-type hardware, the double-threaded "turnbuckle" concept was employed throughout the Mod- 0 and Mod-1 development test programs, thus providing an added adjustment capability :0 accommodate assembly tolerances. It was recognized early, however, that the "turnbuckle" design could not readily be sealed, and a parallel effort was initiated to perfect. a better $W R$ solution. 
Beginning with the Mod-1 design, the use of burst discs to achieve hermetic seal was incorporated under the squib initiator (MC2949) and in each of the two discharge ports at the generator ends. Since their use affected ballistic performance of the GG assembly, they were incorporated in the "turnbuckle" test version furnished by Thiokol, even though hermetic sealing was not a requirement per se of the relatively short-lived test units. They also fabricated trieir GG case parts from 4340 steel, since there was not a strict 1 imitation on component weight in the test vehicles. Thiokol's Drawing E29475 shows the operational test version of the GG assembly that was enployed ior the Mod-1 ground and flight test series.

Because overall RCS weight was e constraint in the WR design (not to exceed $40 \mathrm{lb}$ ), the eventuai use of titanium for the GG case parts, valve bodies, and nozzle extersions was decided upon early in the RCS development program. Independent of our contract with Thiokol for the Mod-1 development units, Sandia launched a separate prog:am to develop a titanium WR generator design that would be cost effective asi well as being optimized for structural and environmental considerat:ons.

Following an analysis done by $D$. R. Chenoweth, 8124,4 a leak rate criterion of $3 \times 10^{-4} \mathrm{~cm}^{3} / \mathrm{sec}$ He was determined to be tolerible, and a bolted joint/mechanical seal design was initiated in garly 1977. Assembly Drawing K99362 shows the first version of a bolted joint design/incorporating tine following features:

a. Constrained by the existing size of the propellant cartridge and a maximum allowable 7-in. external diameter for the GG assembly, an end-joint design was configured using both 24 and $30 \$ 10-32$ high-strength bults.

b. A metal C-ring made by Advance Products Compariy was employed to effect the combined low pressure hermetic seal and the high pressure/high temperature operitional seal required.

c. Because of shelf-life concerns for the bond that held the propellant cartridge in place for all previous Mod-0 and Mod-1 development generators, a mechanical retention concept was substituted. It involved aciding a grip shoulder and 0 -ring seal groove to the outer end of the ABS cartridge liner, plus an RTV serrated "snubber" bind to the other end. These combined to give axial and rutial support..against external dynamic loads, as well as providing internal sealing against circulating hot gas flow that would cause back heating of the propellant grain.

d. Both the main case and closure cover were fabricated frai premachined Ti-6Al-4V forsings that then had the port flanges, squib insert, support lugs, and rupture discs electron-beam welded in place. This procedure required exterive precision machining and exacting process control operations :o achieve final dimensions and sound welds. 
e. A commer :ially available "Shock Strut" valve was added to the lower end of the GG assembly to facilitate leak testing, purging, and/or back filling as might be required in the final WR design.

Five of these welded end-joint designs were fabricated and test evaluated during the early-to-late 1977 tine frame. Results of both hydrostatic proof tests and three hot-gas firings (GTU-38, -39 , and -40 ) were very encouraging, but the relative high cost of welded/forging construction became of increasing concern. As a result of MOOG's investigation into using titanium castings for the valve parts, we became interested in their application to the GG design. The possible use of precision case material offered the following potential advantages:

a. Significant cost savings could be realized from the reduction in machining time and the elimination of welding operations. The entire outsice contour, including port flanges and support lugs, could be cast to size.

b. The relative freedom to cast any shape desired permitted optimizing the wall thicknesses to achieve a more unifon stress design. (The prior welded design dictated uniform wall thickness to accommodate uniform weld penetration.)

While it is true that castings in general enjoy a rather ind ifferent reputation for realiability in highly stressed applications, titanium is one of a small class of materials for which the simple engineering properties as-cast are nearly the same as wrought. (Even the anxiety over casting defects tends to be exaggerated because properly chilled as-cast titanium is tougher than wrought. If the casting defects (shrinkage and porosity) can be eliminated or placed in innocuous regions by careful design of the castings, and/or healed by hot isostatic pressing, castings should be as reliable as forgings. Besides, 100\% proof testing of all production GG case assemblies would alleviate the concarn for defect influence, since the high generator burn pressure lasts for only 3 seconds maximum.)

Figure 8 shows the second and final version of a Mod-2/MC3212 (WR) bolted-joint $G G$ design bised on using Ti-6A)-4V investment castings. The bolted joint was relocated to the center of the assembly, making both halves symnetrical in shape and, therefore, machinable from a single casting definition. The center grip of the propellant cartridge also facilitated better stress distribution of the thermally indused loads through the $A B S /$ propellant bond line. Cast ribs were added to each side of the bolted joint to support the bending moment and reduce iet rotation at the sealing surfaces. Note that all wall thicknesses are nonuniform, thus accommodating in part the nonuniform stress distribution that revealed itself in the finite element analysis. 5

Based on the afomentioned design layout, castings were ordered from Titech, Inc., in early July 1977 (P.0. 18-2213). At the time of program canceliation, partial deliveries had been made and the first set of castings has been machined for testing purposes. Because this casting process was thought to have potential application in future weapon 


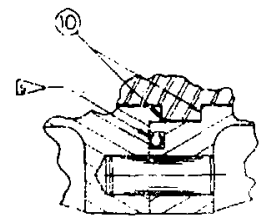

SE: $1, \cdots, A-A$

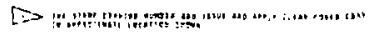

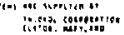

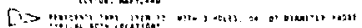

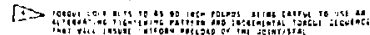

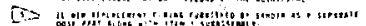

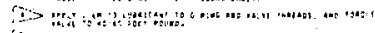

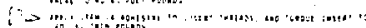

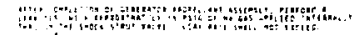

?!:

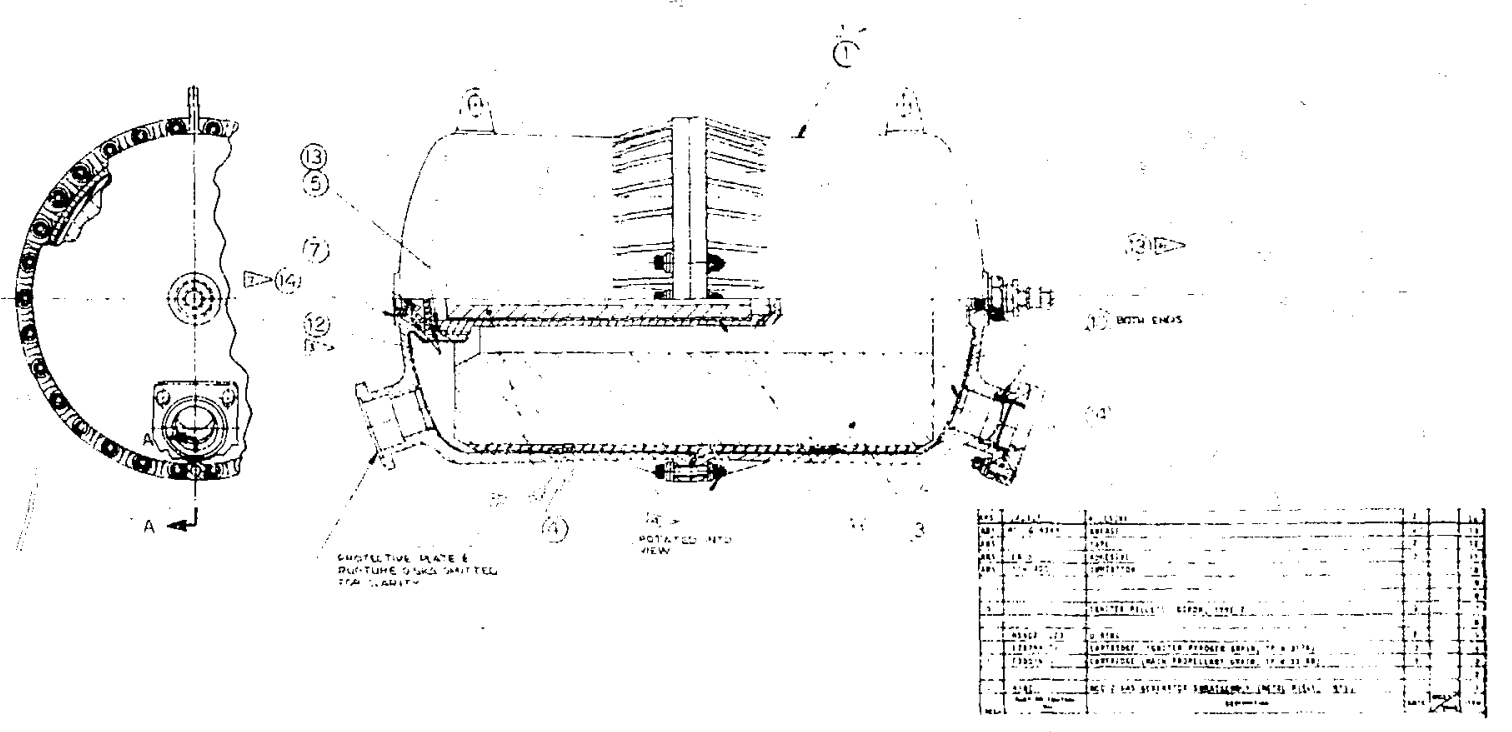

Figure 8. Mod-z Gaas Generátor Assembly (MC321?) 
designs, it was judged worthy of continued effort to conclude the planned evaluation program. Therefore, the contract with Titech was not terminated, and Materials Organization $83: 2$ assumed responsibility to carry the evaluation program to its logical conclusion.

In surmary, the overall Mod-2 RCS system as shown in Figure 9 reflects the intended third and final development phase prior to WR production. It never came to siate of hardware realization because of the sudden B77 carcellation (except for the limited achievement in the titanium GG development program). WR-l ike drawings and specifications were generated only for the MC321n dual control/relief valve assembly (AY211062 and PS211062), since they were required to support Bendix's AER efforts to "tool up" MOOG-East for eventual production buy of the valves.

One systein innovation that was thought of just prior to prngram cancellation was the inclusion of an "after-burner" concept to the thrust nozzles. By introducing oxygen piped into the nozzle extensions just beyond the throat diameters, the still combustible exhaust gages could be made to burn again, yielding another potential thrust increase of about 20-25\%. "Afterburning" would also have the added benefit of converting the objectionable ol ack smoke (unburned hyórocarbons) to a more palatable white color. The higher burn temperatures would be encountered only in the expansion nozzles where they could be tolerated. Thiokol had confirmed that the idea was, feasible, and plans were being formuiated to evaluate a Mod-1 ground test unit when program termination occurred.

Test Results

The foliowing sections briefiy outitine the functional tests performed with the roll control system. Included is a description of the basic test parameters, the test objectives, and the test results.

\section{Cold Gas Rol1 Control Testing}

The initial tescing of the cold gas roll control system was performed in SLL's Flight Dynamics Laboratory (FDL). The reaction systerl and the control electronics were modeled on the FOL hybrid computer system in order to establish the feedback control parameters and investigate system perfomance. Subsequently, d number of tests were performed with the actual cold gas system in the FDL. A complete description of the tests and the test hardware can be found in a memn to S. G. Cain, 8412, from M. H. Rogers, 8158, dated October 28, 1974, title "FDL Test of the B77 Cold Gas Roll Control System." The test results indicated that the system produced approximately $136 \mathrm{ft}-7 \mathrm{~b}$ peak torque and would be able to return a tes jehicle to 0 degrees from an initial rol? position of 90 degrees. This testing also verified the control parameters to be used on the scheduled flight tests of this roll control system. 


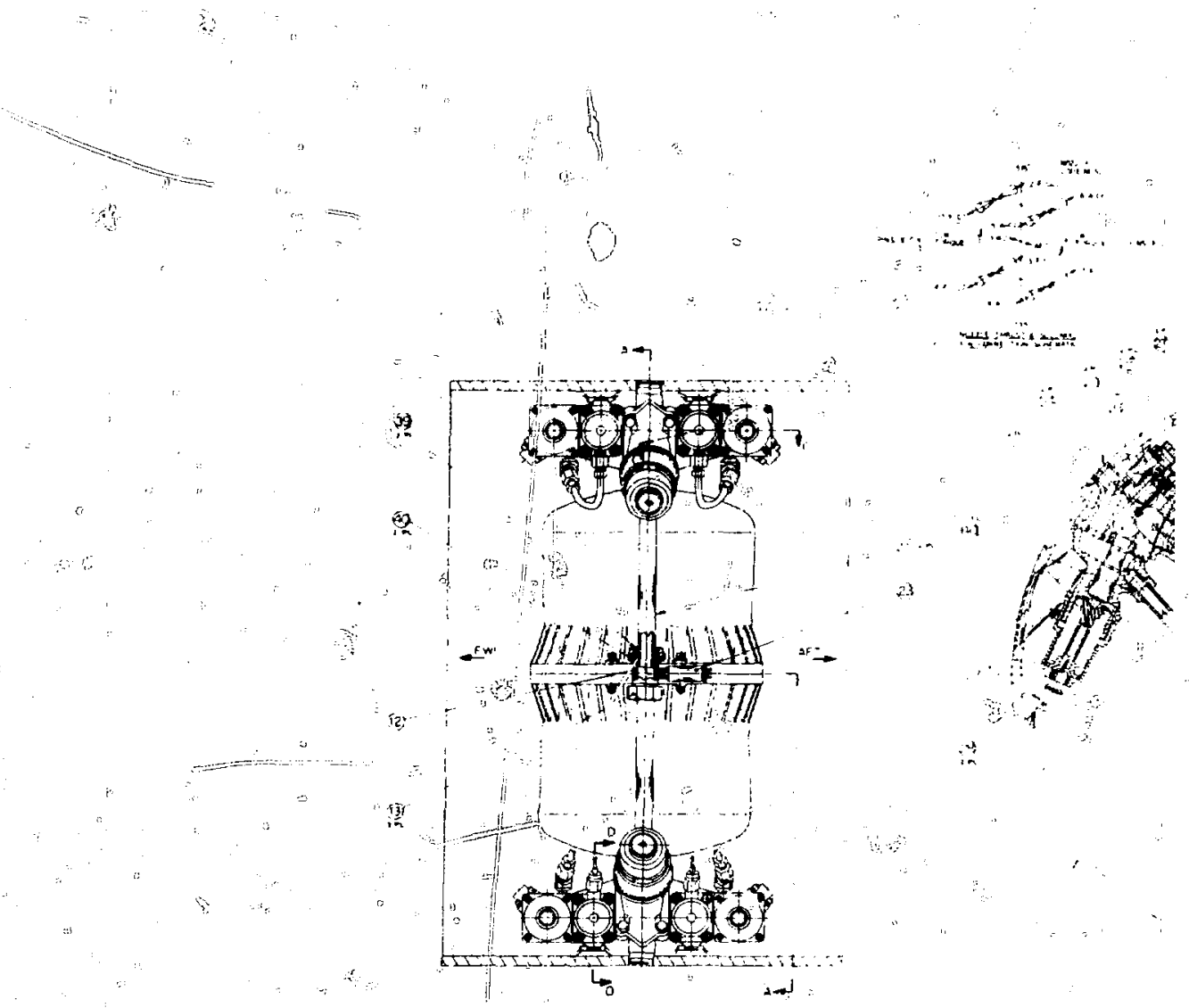



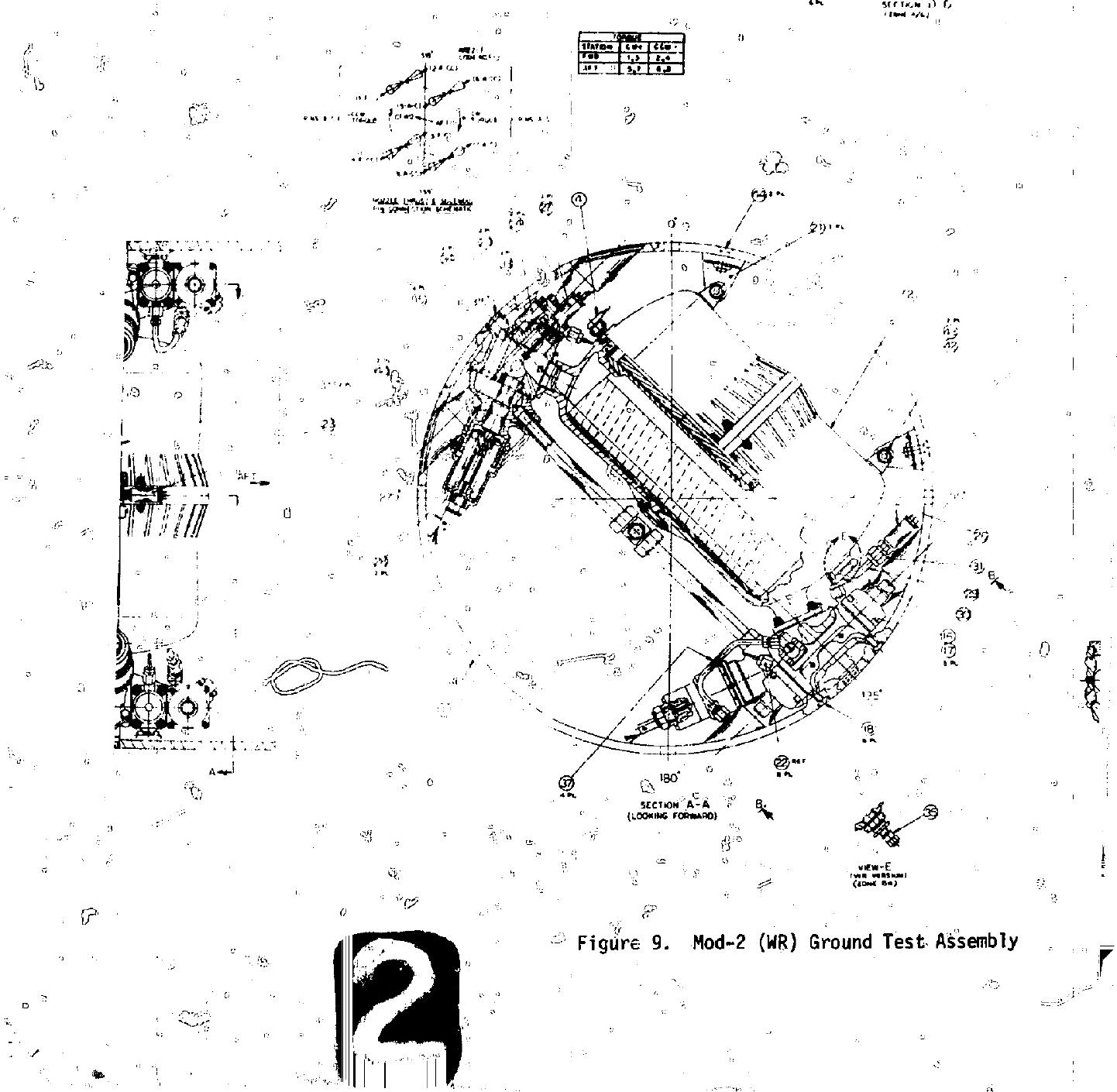


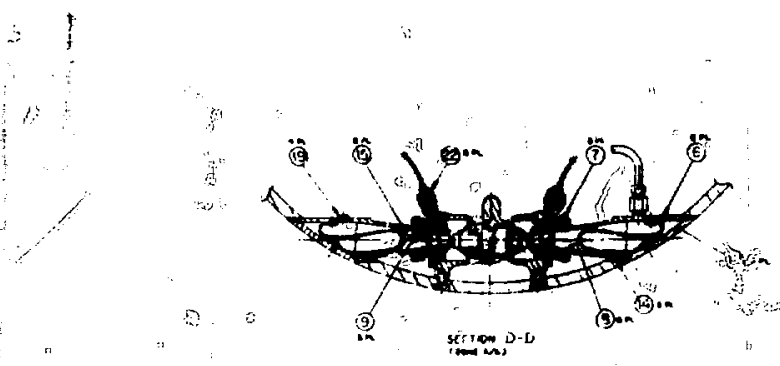

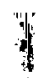

F证

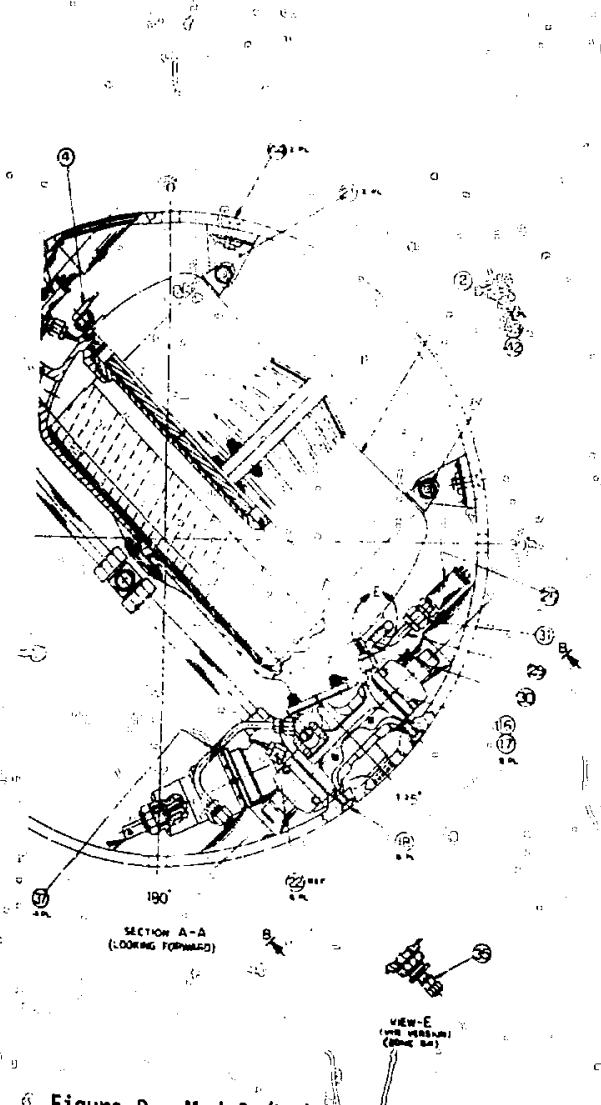

"日勺)

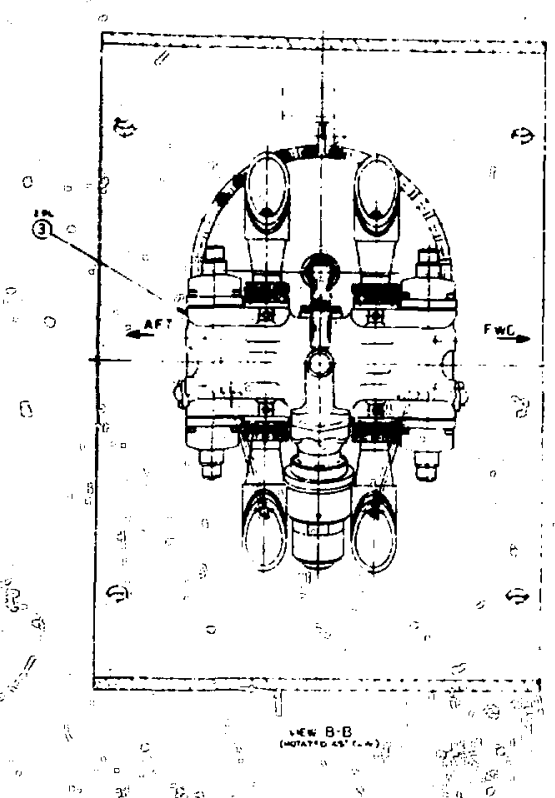

fEigure 9. Mod-2 (WR) Grolind Test Assembly

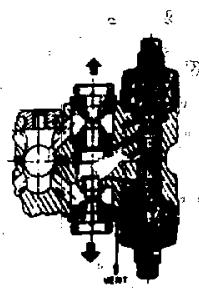

$\ddot{c}=\operatorname{secton} c-c$
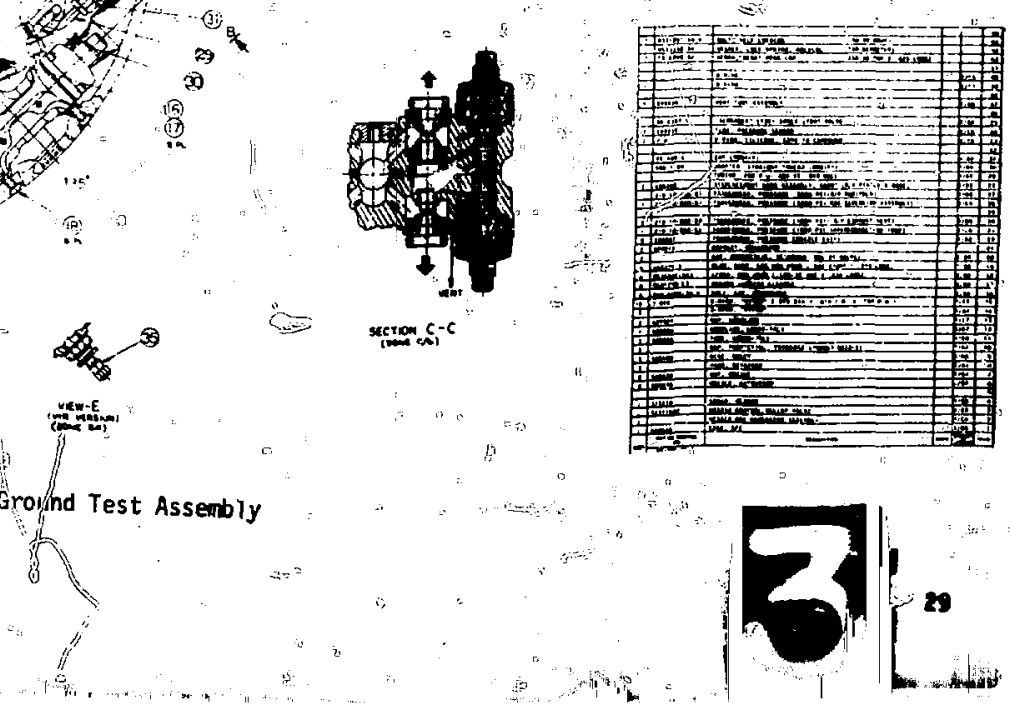
The B77 cold gas roll contro? systen was succeisfully flight tested on two drops from an F-4 aircraft. These tests, PTU-3 and PTU-23, demonstrated that it is feasible to use a reaction sj'stem for rol! control of the B77 and verified the analytical models used to uredict systen performance. Test results also provided data regarding the degradation of roll control thrust due to jet/fin interaction. "Two reportis by Schultz provide complete documentation of the flight test results.6

\section{Mod-0 Warm Gas Roll Control Testing}

The Mod-0 B77 warm gas roll controi systenl previously described underwent two functional ground tests at the Tonopah Test Range th evaluate system performance. These ground, tests, GTU-16 and GTU-17, provided significant data regarding the dynamic perfomance of the Mod-0 system and met the following program objectives:

1. Verified the performance of the roll control gas" generator and servo valves under dynanic conditions.

2. Provided data for the computational models developed to prejict; system performance.

3. Functionally verified the control algorithm and proved system stability.

4. Experimentally tested the roll control maneuver to be flown on parachute test unit (PTU)-14.

These ground tests are described in grazter detail elsewhere. ${ }^{7}$ The resulting test data are available on the B77 Data Bank.

From June 17, 1976 through Decenber 8, 1977 there were a tolal of 12 aircraft drop tests of a $B 77$ test vehicle which incorporated the Mod-0 warm gas roll control system. This drop test series, conducted from different Air Force and Navy aircraft over a wide range of delivery speeds and altitudes, demonstrated the performance of the Mod- 0 system. The rasults of each test are briefly summarized below. Additional test information is available from ithe test unit pretest report, thest report, and the-B7? data files.

PTU-14 (6/17/76), F-4, 425 KCAS): The roll control system was programmed to perform $a+15$ and a -15 degree roll of the test vehicle to investigate jet/fin interaction at a small angle of attack ${ }_{0 / 3}$ The experiment was successfully conducted and the data sfiuwed a roll torque degradation of approximately $25 \%$.

PTU-19 (8/31/76), 8-52, ( 300 KCAS): The system was progr the test unit to the upright position from an initial carriage angle of 35 degrees. The roll control system properly oriented the test vehicle and maintained the unit upright within $+/-7$ degrees through the lifting parachute phase. The effective roll torque was degraded by approximately $35 \%$ as a result of jet/fin interaction. 
PIU-56 (10/28/75, F-4, 575 KCAS): This unit was programmed to perform a $+/-15$ degree roll manewer to investigate jet/fin interaction at a large angle of attack. Beciasse of a problem with the banb ejection mechanism on the aircraft, the maximum angle of attack achieved was limited to 10 degrees. At this angle of attack and velocity the effecitive roll torque was reduced by an average of $23 \%$.

PTU-16 (11/9/76, F-4 700 KCAS): The roll control system functioned per design intent and maintained the test vehicle upright with in $+1-2$ degrees until the lifting parachute was deployed. Subsequently, the parachute daminated the roll behavior of the bonb/parachute system and the vehic? e rolled to 45 degrees. The cause of this roll behavior has not yet been fully explained.

PTU-18(12/7/76, F-4 300 KCAS): The roll control system finctioned properly and maintained the test vehicle upright within $+/-5$ degrees through the lifting parachute phase of the test.

PTU-15 (4/5/77, F-111 a 425 KCAS): This test was the first demonstrated use of the roll control system in the spin-up mode. The test vehicle was successfully spun to 4 revolutions per second with a 2-second torque impulse from the gas generator.

PTU-54 (7/6/77, F-4 740 KCAS): The roll orientation of the test vehicle was maintained upright within $+/-10$ degrees except for a brief ecursion to 17 degrees when the lifting parachute was deployed. This test was the first operational use of the F-1 programiner, which implemented the WR control algorithm and used the SA2590 rate gyro to supply vehicle roll information. All roll control system components periormed as expected.

PTU-77 (7/8/77, F-4 a 300 KCAS): PTU-77 was the first 877 test vehicle to be inipacter against a hard target and del ivered from 100 feet abave ground 1Eel. The roll control system, using a simplified electroric control package, inaintained the vehicle upright within $+/-10$ degrees through the test. A complete assessment of control system perfomance was not possible because of the limited telemetry instrumentation.

PTU-40 (7/14/77), F-111 a 290 KCAS): This test unit was used to study the interaction between the roll control jets and the F-111 delivery aircraft. Samples obtained both on the externa! surfaces of the aircraft and by a gas sampler inside the cockpit indicated no measureable contamination of the aircraft, Other aspects of the roll control system performance were within acceptable linits, with the test vehicle being controlled to within 5 degrees of upright through the first-stage parachute phase of the test.

PTU-78 (10/12/77), B-52 a 370 KCAS): This test unit was delivered fran an operational SAC B-52 bomber against the hard target at the Tonopah Test Range. The control system, identical to that Lsed on PTU-7\%, maintained the test vehicle upright within 10 degrees through the initial 3.5 seconds of the test. 
i.

PTU-36 (11/4/77), F-4, 300 KCAS): The telenetry instrumentation indicated that al roli contral system components functioned per design intent. The test vehicle was maintained upright through the lifting parachute phase within 8 degrees except for a brief excursion to -15 degrees when the lifting parachute was deployed.

PTU-80 (12/8/77), FB-111 @ 350, KCAS): This iest unit was similar to PTU-77 and PTU-78 in terms of the rol control system used. From the limited on-board instrumentation, all roll control system components functioned properly.

The 2 ground test $y$ and the $12 \mathrm{flight}$ tests of the Mod-0 roll control system demonstrated the fefsibility of using a warm gas system to control the roll orientation of the $B 7 \overline{7}$ bomb/parohute system. This test series also verified the computational models being used to predict system performance and demonstrated the stability.and capability of the WR control algorithm.

Mod-1 Warm Gas Roll Control Testing

The Mod-1 B77 warm gas roll control system was subjected to an extensive functional test series prior to any flight testing. These ground tests (GTU-18, $-19,-20,-38,-39$, and -40 ) were intended to evaluate system. performance over the wide range of environmental conditions specified for the 877. The following major program objectives were accomplislied during this test series.

1. The gas geperator performance was evaluated at precond itioned temperatures of $180^{\circ} \mathrm{F}$ and $-65^{\circ} \mathrm{F}$.

2. The structural integrity of the generator case and propellant grain was proven adequate for vibration and shock conditions designed to duplicate the 877 environmental specifications and the parachute deceleration loads.

3. It demonstrated the ability of a single refief valve to vent the gas generator properly and prevent catastrophic structural failure.

4. The static torque output was determined to be approximately 360 foot pounds for a system operating at 1800 psi and 450 foot pounds for a 2200 psi operating pressure.

5. Spin up to 8.5 revolutions per second was demonstrated and caused little performance degradation.

This ground test series did uncover two problems with the Mod-1 design. The results of four tests showed a tendency for the generator pressure to oscillate at 20 to $50 \mathrm{~Hz}$ within a pressure band of 300 to $400^{\prime} \mathrm{psi}$. The oscillations are believed to be caused by interactions between the dual relief valves and the propellant burn characteristics. At the time the program was cancelled, work had begun at Thiokol and at. Sandia to develop a mathematical model of the gas generator/rel ief valve system in order to isolate the contributing causes. 
This oscillation tended to produce a dither of the relief valves, which aided in overconing striction and resulted in better pressure regulation. However, it was disturbing not to know the cause of the oscillation and its sensitivity to various system parameters, so the analys is effort was being initiated. A second problem, al so not resolved, was the two separate occasions where the first stage of a servo valve lodged in the activated position and made that valve inoperable. Both occurrences were during the comparatively long activation of the value during a spin-up test and were partially attributed to the buildup of combustion products in the primary stage of the valve. Programs were underway to resolve these problems prior to release of the Mod-2 design.

In late January 1978, two flight tests of the Mod-1 roll control system were conducted. These tests demonstrated the performance and capabilities of the new design.

PTU-37 (1/24/78, F-4, a 750KCAS): PTU-37 was: the first:"flight test application of the Mod-1 roll control system. The teit vehicle roll orientation was maintained within 10 degrees of upright except for a 0.7 -second excursion to 39 degrees just after deployment of the 1 ifting parachute. The general performance of all system components, including the F-l programmer, was well within design goals. The gas generator pressure oscillation previously encountered with the Mod-1 system also occurred on this test but lasted only $0.3 \mathrm{sec}$. The teilemetry data indicated that the system perfonance was not degraded by this oscillation. This test deminstrated feasibility of operating the roll control system at 2200 psi, which results in approximately .450 foot pounds of torque.

PTU-20 (1/25/78, F-4 300 KCAS): PTU-20 demonstrated the Mod-1 performance when operated at 1800 psi to froduce 360 foot pouns of torque. The test vehicle was maintained upright except for a $0.3-$ sec excursion to 23 degrees. All system componersts perfonmed as expected and, again, the pressure oscillation occurred for approximately 0.3 seconds.

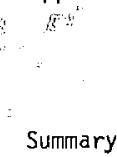

The design of the $B 77$ roll control system progressed from the original: cold gas system devised in 1975 through the Mod-2 design just canpleied at the end of 1977. An extensive ground and flight test series proved the capability of both the Mod-0 and Mod-1 designs to meet the B77 system requirements. The problem of gas generator oscillation and the sticking valves discovered during the Mod-1 testing remain to be resrived. A number of other tasks, including final optimization of the control algorithm, assessment of jet/fin interaction and its impact on system perfomanse, and final resolution of the undesirable yaw forces produced by the roll control jets need to be accomplistied. The success of the flight test series indicates that the system design as it was proposed would have readi?y supported the remainder of the B77 flight test schedule and accomplished the major B77 system objectives. 
1. C. W. Peterson and R. N. Everett, private communication.

2. "M. H. Rogers, "An Analytical Model of a Single Axis Alltitude Roll Control System," Sandia Laboratories Report SAND77-8256, 1977.

3. MOOG Design Evaluation Report \#MR887," November 30, 1966.

4. (l). R. Chenoweth, "Hermetic Seal of the Gas Generator in the B77 Roll "Control System," Sandia Laboratories Report SAND77-8238, 1977.

5. Y. R. Kan, private communication.

6. R. H. Schultz, "Aircraft Drop Test of B77 Parachute Test Unit PTU-3," Sandia Laboratories Repert SAND75-8064, 1976, and "Aircraft Drop Test of B77 Parachute Test Unit PTU-23, Sandia Laborataries Report SAND75-8066, 1976.

7. M. H. Rogers, "Pretest Report on GTU-16," January 15, 1976 and "Pretest Report on GTU-17," March 15, 1976, unpublished.

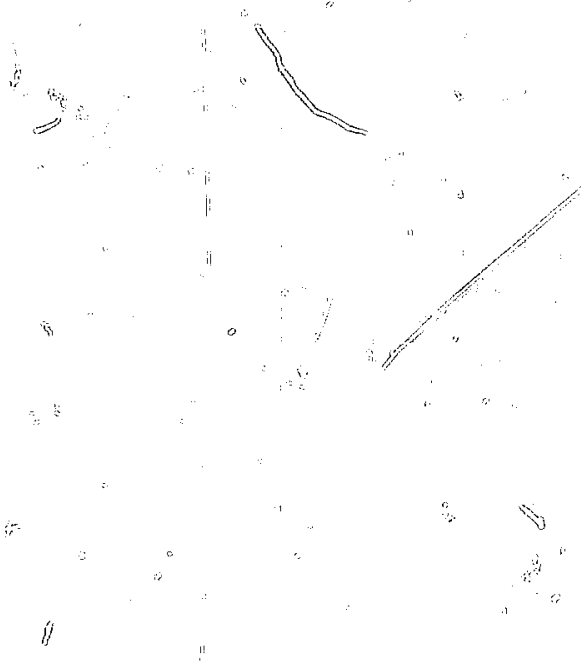


UNEIMITED RELEASE

INITIAL DISTRIBUTION

R. L. Peurifoy, 4300

D. B. Shuster, 5600

R. D. Andeas, 5622

D. J. Rigali : 5623

T. B. Cook, 8000; Attn:

A. N. B1 ackwel ?, 8200

B. F. Murphey, B300

L. Gutierrez, 8400

W. J. Spencer, 8100 ; Attn: J. Bariam, 8110

A. L. Jones, 8116; Attn: W. R. Bolton

W. E. Al zheimsr, 8120; Attn: Y.-R: Kan, 8123

J. L. Wirth, 8150

G. N. Beeler, 8152

R. D. Cozine, 8160 , Attn:

M. H. Reynolds, 8161

J. S. Anderson, 8166

M. 0. Jones, 8168
A. S. Rivenes, 8162
M. H. Rogers, 8162 (2)
D. R. Adolphson, 8312
S. G. Ca in, 8412
D. E. Grejson, 8440
C. J. Pignolet, 8451 (2)
l.. A. Hiles, 8466

Publications and Public Information Division, 8265, for TIC (2)

F. J. Cupps, 826/Technica! Library Processes Division, 3141

Technical Library Processes Division, 3141 (2)

Library and Security Classification Division, 8266 (3) 